\title{
Biodegradation of pharmaceuticals in hospital wastewater by a hybrid biofilm and activated sludge system (Hybas)
}

Escola Casas, Monica; Chhetri, Ravi Kumar; Ooi, Gordon Tze Hoong; Hansen, Kamilla Marie Speht; Litty, Klaus; Christensson, Magnus; Kragelund, Caroline; Andersen, Henrik Rasmus; Bester, Kai

\section{Published in:}

Science of the Total Environment

Link to article, DOI:

10.1016/j.scitotenv.2015.05.099

Publication date:

2015

Document Version

Peer reviewed version

Link back to DTU Orbit

Citation (APA):

Escola Casas, M., Chhetri, R. K., Ooi, G. T. H., Hansen, K. M. S., Litty, K., Christensson, M., Kragelund, C., Andersen, H. R., \& Bester, K. (2015). Biodegradation of pharmaceuticals in hospital wastewater by a hybrid biofilm and activated sludge system (Hybas). Science of the Total Environment, 530-531, 383-392.

https://doi.org/10.1016/j.scitotenv.2015.05.099

\section{General rights}

Copyright and moral rights for the publications made accessible in the public portal are retained by the authors and/or other copyright owners and it is a condition of accessing publications that users recognise and abide by the legal requirements associated with these rights.

- Users may download and print one copy of any publication from the public portal for the purpose of private study or research.

- You may not further distribute the material or use it for any profit-making activity or commercial gain

- You may freely distribute the URL identifying the publication in the public portal 
1

\title{
Biodegradation of pharmaceuticals in hospital
}

\section{wastewater by a hybrid biofilm and activated sludge}

\author{
system (Hybas)
}

\author{
Mònica Escolà Casas ${ }^{1}$, Ravi Kumar Chhetri ${ }^{2}$, Gordon Ooi $^{1}$, Kamilla M. S. Hansen ${ }^{2}$, Klaus \\ Litty $^{3}$, Magnus Christensson ${ }^{4}$, Caroline Kragelund ${ }^{3}$, Henrik R. Andersen ${ }^{2}$ and Kai Bester ${ }^{{ }^{*}}$ \\ 1) Environmental Science, Aarhus University, Frederiksborgsvej 399, 4000 Roskilde, Denmark \\ 2) Department of Environmental Engineering, Technical University of Denmark, Miljøvej 113, \\ 2800 Kgs. Lyngby, Denmark
}

3) Department of Chemistry and Biotechnology, Danish Technological Institute, Kongsvang Allé 29, 8000 Aarhus C, Denmark

4) AnoxKaldnes, Klosterängsvägen 11A, 22647 Lund, Sweden 


\section{Abstract}

Hospital wastewater contributes a significant input of pharmaceuticals into municipal wastewater. The combination of suspended activated sludge and biofilm processes, as stand-alone or as hybrid process (Hybrid biofilm and activated sludge system ( Hybas $\left.^{\mathrm{TM}}\right)$ ) has been suggested as a possible solution for hospital wastewater treatment. To investigate the potential of such a hybrid system for the removal of pharmaceuticals in hospital wastewater a pilot plant consisting of a series of one activated sludge reactor, two Hybas ${ }^{\mathrm{TM}}$ reactors and one moving bed biofilm reactor (MBBR) has been established and adapted during 10 months of continuous operation. After this adaption phase batch and continuous experiments were performed for the determination of degradation of pharmaceuticals. Removal of organic matter and nitrification mainly occurred in the first reactor. Most pharmaceuticals were removed significantly. The removal of pharmaceuticals (including x-ray contrast media, B-blockers, analgesics and antibiotics) were fitted to a single first-order kinetics degradation function, giving degradation rate constants from 0 to $1.49 \mathrm{~h}^{-1}$, from 0 to $7.78 \times 10^{-1} \mathrm{~h}^{-1}$, from 0 to $7.86 \times 10^{-1} \mathrm{~h}^{-1}$ and from 0 to $1.07 \times 10^{-1} \mathrm{~h}^{-1}$ for first, second, third and fourth reactor respectively. Generally, the highest removal rate constants were found in the first and third reactor while the lowest were found in the second one. When the removal rate constants were normalized to biomass amount, the last reactor (biofilm only) appeared to have the most effective biomass in respect of removing pharmaceuticals. In the batch experiment, out of 26 compounds, 16 were assessed to degrade more than $20 \%$ of the respective pharmaceutical within the Hybas ${ }^{\mathrm{TM}}$ train. In the continuous flow experiments, the measured removals were similar to those estimated from the batch experiments, but the concentrations of a few pharmaceuticals appeared to increase during the first treatment step. Such increase could be attributed to de-conjugation or formation from other metabolites.

\section{Keywords}

Hospital wastewater, MBBR, X-ray contrast media, Pharmaceuticals, Removal rate constants 


\section{Introduction}

Hospitals represent a substantial point source for pharmaceuticals discharged to the municipal sewer system and the wastewater from hospitals is usually co-treated together with municipal wastewater (Santos et al., 2013; Verlicchi et al., 2010; Thomas et al., 2007). Earlier studies have shown, that conventional activated sludge treatment in WWTPs is inefficient for full removal of pharmaceuticals (Ternes et al., 2004; Joss et al., 2006). Thus, source-treatment of hospital wastewater has been proposed in industrialized and developing countries to decrease the quantity of pharmaceuticals discharged to municipal WWTPs (Verlicchi et al.; 2010; 2015; Pauwels and Verstraete; 2006). This source-treatment proposal gets more important when it comes to big hospital sizes.

It is mainly due to pathogen-spreading concerns that countries like China and Japan are currently treating hospital wastewater based on conventional activated sludge process or MBR (Membrane Bioreactor) (Pauwels and Verstraete, 2006; Liu et al., 2010). There are only a few studies on hospital wastewater were the removal of pharmaceuticals is described:: Marienhospital Gelsenkirchen and Waldbröl (Germany), Isala clinics in Zwolle (The Netherlands), Cantonal Hospital of Baden (Switzerland) (Pills, 2012), Ioannina hospital (Greece) (Kosma et al., 2010) and Herlev hospital (Denmark) (Nielsen et al., 2013). Processes based on activated sludge are, however, not sufficient to ensure high removal of pharmaceuticals, which means that additional posttreatment is required. Numerous post-treatment processes like activated carbon, ultraviolet photolysis, advanced oxidation processes (AOPs), reverse osmosis or nanofiltration can remove pharmaceuticals from wastewater (Pauwels and Verstraete, 2006; Joss et al., 2008). In some treatments based on membrane bioreactors with sludge (MBR), the systems were accompanied with AOPs or ultraviolet photolysis to be effective (Nielsen et al., 2013; Köhler et al., 2012; Kovalova et 
al., 2013; Kovalova et al., 2012). Fungal fluidized-bed bioreactors were also tested for pharmaceuticals removal in hospital wastewater (Cruz-Morató et al., 2014), and presented better efficacy than the activated sludge systems. Finally, suspended biofilm systems such as MBBRs (Moving Bed Biofilm Reactors) have appeared to directly remove pharmaceuticals from hospital wastewater (Escolà Casas et al., 2015).

Different biofilm technologies have recently appeared as an effective tool to remove micropollutants with the main focus being on porous media biofilm processes i.e., slow sand filter e.g. (Bester and Schafer, 2009; Escolà Casas and Bester, 2015; Heberer et al., 2004; Hijosa-Valsero et al., 2011; Janzen et al., 2009; Li et al., 2014; Reungoat et al., 2011; Zearley and Summers, 2012). Along with such biofilm technologies, MBBR also seemed to be a promising solution to remove micro-pollutants, which cannot be removed with activated sludge treatment (Hapeshi et al. 2013; Zupanc et al. 2013; Falås et al. 2012; Falås et al. 2013; Escolà Casas and Bester 2015).

Hybas $^{\mathrm{TM}}$ is a hybrid process, based on the integrated fixed-film activated sludge technology, where polyethylene carriers for biofilm growth are suspended within activated sludge in one reactor (Christensson and Welander, 2004; Ødegaard et al., 2014). Such carriers are already in operation for nitrification and denitrification processes. In this way, Hybas ${ }^{\mathrm{TM}}$ contains two separate biomasses: one with low sludge age (activated sludge flocks), and one with high-sludge age (attached biofilm on MBBR-carriers). This fact allows fast growing biomass to be in the form of activated-sludge flocks, while the slow-growing biomass develops on the MBBR carriers. The presence of attached biofilm in wastewater treatment systems have shown to improve the activated sludge performance for nutrient removal (Debabrata, 2010, Randall and Sen, 1996). Falås et al., 2013 demonstrated that 
attached biofilm contributes significantly to the overall removal of micro-pollutants in a Hybas ${ }^{\mathrm{TM}}$ system.

According to the literature, Hybas ${ }^{\mathrm{TM}}$ treatment seems to be a promising option to treat hospital wastewater. Therefore, this study tested and evaluated for the first time the performance of a pilot Hybas $^{\mathrm{TM}}$ plant for the removal of pharmaceuticals from mechanically pre-treated hospital wastewater.

\section{Materials and Methods}

\subsection{Treatment system}

A lab-scale treatment line was established to treat a portion of the wastewater produced at the oncology section of Aarhus University Hospital. The line consisted of four three liter reactors in series $(\mathrm{H} 1, \mathrm{H} 2, \mathrm{H} 3$ and $\mathrm{P}) . \mathrm{H} 1$ contained only activated sludge, $\mathrm{H} 2$ and $\mathrm{H} 3$ contained activated sludge and biofilm carriers and $\mathrm{P}$ was a polishing step containing only biofilm carriers. Each reactor $(\mathrm{H} 2, \mathrm{H} 3$ and $\mathrm{H} 4)$ contained 500 AnoxKaldnes ${ }^{\mathrm{TM}} \mathrm{K} 5$ carriers (AnoxKaldnes, Lund, Sweden) and resulted in a filling ratio of 50\%. The set-up is drawn in Figure 1. The mixing was performed using aeration and the wastewater was pumped at $0.95 \mathrm{~L} \mathrm{~h}^{-1}$ flow into the treatment line. Sludge recycling rate from the settler to $\mathrm{H} 1$ was $100 \%$.

The raw hospital wastewater was passed through an $80 \mu \mathrm{m}$ filter from Amiat Water Systems (Bochum, Germany) using a monopump (Pump 1) from Seepex (Hillerød, Denmark) into the mixing tank $(100 \mathrm{~L})$. This equalization tank maintained a temperature between $15^{\circ} \mathrm{C}$ and $18^{\circ} \mathrm{C}$ and its function was to level out the flow and dynamics in the loading over the day as there was regularly low flow during nights in the sewage pipe. Using a peristaltic pump (Pump 2) from Watson-Marlow (Ringsted, Denmark) the water was pumped from H0 to H1. The main parameters 
of the wastewater ( $\mathrm{pH}$, oxygen, temperature, $\mathrm{COD}, \mathrm{DOC}, \mathrm{NH}_{4}-\mathrm{N}, \mathrm{NO}_{2}-\mathrm{N}$ and $\left.\mathrm{NO}_{3}-\mathrm{N}\right)$ were measured regularly.

It was intended to perform BOD removal and nitrification in $\mathrm{H} 1$ and have biofilms operating on low BOD loading in $\mathrm{H} 2, \mathrm{H} 3$ and $\mathrm{P}$ being more adapted to degrade complex and difficult to degrade organic matter that the sludge cannot degrade. It was hypothesised that this might induce an ability to degrade pharmaceuticals that are recalcitrant to sludge treatment.

\subsection{Experimental design}

The study used two different methodologies to experimentally investigate the system's capacity to degrade pharmaceuticals from hospital wastewater. First, a batch experiment was conducted to test which of the spiked compounds could be potentially degraded in the treatment train and to study their degradation kinetics. Then, a continuous flow experiment was performed to mimic the real performance of the system

\subsubsection{Batch experiment}

To work with each reactor of the system as a unit, the flow was stopped by turning off the two pumps (See figure 1). The connecting tubes were also blocked with clamps. As not all compounds are used in a hospital at all times of the each reactor was spiked with a stock solution containing all the target compounds, which achieved nominal concentrations of $14 \mu \mathrm{g} \mathrm{L}^{-1}$ for the pharmaceuticals and $200 \mu \mathrm{g} \mathrm{L}^{-1}$ for the X-ray contrast media to make sure in all reactors was enough for kinetic assessment. After the spiking, from 1 minute to $24 \mathrm{~h}, 10 \mathrm{~mL}$ samples were taken with a glass pipette from each reactor. The concentrations of pharmaceuticals were analysed by HPLC-MS and the 
determined concentrations (resulting from the original plus spiked) were used for further assessment).

\subsubsection{Continuous flow experiment}

A 'volume of water' was monitored through the stages of the system considering the hydraulic retention time. To exclude concentration variations, the inflow of water from the sewer into the equalization tank H0 was stopped (Pump 1; see figure 1) and the reactors received the water from H0. The system worked with native concentrations of compounds (as they occurred in the hospital wastewater). No additional pharmaceuticals were added. $\mathrm{H} 0$ and $\mathrm{H} 1$ were sampled three times during the first 3 hours of the experiment. For the following stages, the hydraulic flow was pursued by sampling in accordance to the hydraulic retention time of the system. Sampling times can be seen in Figure 3.

\subsection{Chemicals}

The compounds used for calibration as well as for spiking in the batch experiments were obtained from diverse suppliers as presented in the supplementary material (S1) along with structures and CAS numbers. The selection was based on a Danish priorisation list of pharmaceuticals of concern adopted to be run all in one chromatographic method to gain best insights into reactor performance. 
The following compounds were analysed:

Antibiotics: Azithromycin, Ciprofloxacin, Clarithromycin, Clindamycin, Erythromycin, Sulfadiazine, Sulfamethizole, Sulfamethoxazole, Trimethoprim

Blood pressure regulators: Atenolol, Metoprolol, Propranolol, Sotalol

Diverse: Carbamazepine, Diclofenac, Ibuprofen, Phenazone, Tramadol, Citalopram, Venlafaxine

X-ray contrast media: Diatrizoic acid, Iohexol, Iopromide, Iomeprol, Iopamidol

And the metabolite Acetyl-Sulfadiazine

Formic acid and gradient grade methanol were from Merck (Darmstadt, Germany); water was obtained from an in-house Millipore apparatus.

\subsection{Quantification of general parameters}

The main parameters were measured frequently in the treatment train. Samples for Dissolved Organic Carbon (DOC), Chemical Oxygen Demand (COD), ammonium nitrogen $\left(\mathrm{NH}_{4}{ }^{+}-\mathrm{N}\right)$, nitrite nitrogen $\left(\mathrm{NO}_{2}{ }^{-} \mathrm{N}\right)$ and nitrate nitrogen $\left(\mathrm{NO}_{3}{ }^{-} \mathrm{N}\right)$ were collected and analysed for all reactors. Subsamples of approximately $50 \mathrm{~mL}$ were filtered with a $0.45 \mu \mathrm{m}$ filter. Samples for DOC were preserved in the freezer until analysis, while samples for COD, $\mathrm{NH}_{4}{ }^{+}-\mathrm{N}$ and $\mathrm{NO}_{2}{ }^{-}-\mathrm{N}$ and $\mathrm{NO}_{3}{ }^{-}-\mathrm{N}$ were analysed the same day.

$\mathrm{COD}, \mathrm{NH}_{4}{ }^{+}-\mathrm{N}, \mathrm{NO}_{2}{ }^{-}-\mathrm{N}$ and $\mathrm{NO}_{3}{ }^{-}-\mathrm{N}$ concentrations $[\mathrm{mg} / \mathrm{L}]$ were analysed on a Hach Lange robot Rohasys, AP 3800 Multi with the application of Hach Lange cuvette tests for COD (LCK 414), $\mathrm{NH}_{4}{ }^{+}-\mathrm{N}(\mathrm{LCK} 303 / 304), \mathrm{NO}_{2}^{-}-\mathrm{N}\left(\right.$ LCK 341) and $\mathrm{NO}_{3}{ }^{-}-\mathrm{N}$ (LCK 339) following the manufacturer's instructions (HACH LANGE GMBH, Düsseldorf, Germany). 


\subsection{Quantification of biomass in suspended sludge and biofilm on carriers}

\subsubsection{Suspended Sludge}

Sludge from Viby municipal WWTP was used for seeding of the Hybas ${ }^{\mathrm{TM}}$ plant. The concentration of suspended solids was kept between $3.0-3.5 \mathrm{~g} / \mathrm{L}$ and fresh sludge was added every two weeks to compensate for losses. The suspended solids were determined by filtering through a paper filter with $0.45 \mu \mathrm{m}$ pore width succeeded by drying and weight determination. The reactors were operated with $100 \%$ sludge recycle thus giving in reality a sludge age of around 20 weeks/140d.

\subsubsection{Biofilm on carriers}

Ten carriers from $\mathrm{H} 2, \mathrm{H} 3$ and $\mathrm{P}$ reactors were placed on an aluminum-foil cup, dried overnight at $105^{\circ} \mathrm{C}$, and weighed. The carriers were then washed in tepid $2 \mathrm{M} \mathrm{NaOH}$ and cleaned with de-ionized water. After washing, the carriers were dried again at $105^{\circ} \mathrm{C}$ overnight and the aluminium cup was weighed with and without carriers. Content of biomass on the carriers was calculated as the weight difference before and after cleaning of carriers. The biomass content per area was calculated knowing that each carrier has a protective surface area of $0.00242 \mathrm{~m}^{2}$.

\subsection{Quantification of pharmaceuticals}

\subsubsection{Sample preparation and analysis}

After each sampling, the samples were stored in a fridge at $4^{\circ} \mathrm{C}$. When the experiment was finished, all samples were transported under cooled conditions to the laboratory. Once there, $3.5 \mathrm{~mL}$ of methanol were added to each $10 \mathrm{~mL}$ sample and put to $-20^{\circ} \mathrm{C}$ while waiting for analysis. When 
analysing, the samples were left to reach room temperature and homogenized. $1.5 \mathrm{~mL}$ subsamples of each sample were transferred to HPLC vials and centrifuged for 10 minutes at $6000 \mathrm{rpm} .900 \mu \mathrm{L}$ of the aqueous phase were taken with a syringe and transferred to a new HPLC vial. $100 \mu \mathrm{L}$ of internal standard were added to each sample with a glass syringe. Finally, the samples were analysed by means of HPLC-MS/MS. Injections of 10 and $50 \mu \mathrm{L}$ were used for the batch and concentration profile experiments correspondingly.

\subsubsection{HPLC-MS/MS}

The concentrations of the pharmaceuticals in the hospital wastewater and the treatment reactors were quantified by means of HPLC-MS/MS. The HPLC had a dual low-pressure mixing ternarygradient system Ultimate 3000 from Dionex. The system operated with a pump of the 3000 series (DGP-3600 M), a 3000 TSL autosampler (WPS 3000 TSL) and a column oven and degasser also from Dionex 3000. The mass spectrometer model was an API 4000 (ABSciex, Framingham, MA, USA). HPLC and MS/MS conditions are stated in the supplementary information (S2).

\subsubsection{Data treatment}

The concentrations of all the compounds over time in the wastewater were plotted. For each experiment, the data was treated in a different way as described in the following lines.

\subsubsection{Batch experiment}

Concentrations were plotted for each reactor and compound. Figure 2 shows nine illustrative compounds while the remaining compounds are shown in the supplementary material (Figure S1). First-order degradation equation (Equation 1) was fitted using GraphPad Prism, with no weighting: 
Equation 1: $\quad C=\left(C_{0}\right) \cdot e^{-k t}$

$C$ expresses initial and concentration, $k$ is the removal rate constant, $t$ stands for time.

The $k$ values of each reactor were used to calculate a removal (\%) of each of the compounds within the treatment train by using Equation 2:

Equation 2:

$$
\frac{C_{P}}{C_{H 0}}=\frac{v_{i}}{\left(1+k_{P} \cdot \tau_{P}\right) \cdot\left(\left(1+k_{H 1} \cdot \tau_{H 1}\right) \cdot\left(1+k_{H 2} \cdot \tau_{H 2}\right) \cdot\left(1+k_{H 3} \cdot \tau_{H 3}\right) \cdot\left(v_{i}+v_{r}\right)-v_{r}\right)}
$$

$C_{P}$ and $C_{H 0}$ express the concentrations in the reactors $\mathrm{H} 0$ and $\mathrm{P}[\mu \mathrm{g} / \mathrm{L}]$ correspondingly, $k_{i}$ express the removal rate constants $\left[\mathrm{h}^{-1}\right]$ in the $\mathrm{H} 1, \mathrm{H} 2, \mathrm{H} 3$ and $\mathrm{P}$ reactors. $\tau_{\mathrm{i}}$ refers to the hydraulic residence times [h] of $\mathrm{H} 1, \mathrm{H} 2, \mathrm{H} 3$ and $\mathrm{P}$ reactors while $v_{\mathrm{i}}$ and $v_{\mathrm{r}}$ describe the inflow and recirculation flows $[\mathrm{L} / \mathrm{h}]$ respectively.

As expressed on Equation 3, the hydraulic residence time for H1, H2 and $\mathrm{H} 3$ was the same and can be found as the tank volume divided with the sum of inflow and recirculation flows. For the last reactor $(\mathrm{P})$, the hydraulic residence time was different than $\mathrm{H} 1-\mathrm{H} 3$ and can be calculated as tank volume divided with inflow.

Equation 3:

$$
\tau_{H 1}=\frac{\text { Tank volume }}{v_{i}+v_{r}}=\tau_{H 2}=\tau_{H 3} \neq \tau_{P} ; \tau_{P}=\frac{\text { Tank volume }}{v_{i}}
$$


Compounds giving estimated removals over $20 \%$ during the treatment system were considered to be degradable.

\subsubsection{Continuous flow experiment}

The concentrations measured during 3 hours in each reactor were represented in a plot. Figure 3 shows four representative compounds. The removal (\%) was calculated by comparing concentrations from $\mathrm{H} 0$ to $\mathrm{H} 1, \mathrm{H} 2, \mathrm{H} 3$ and $\mathrm{P}$ according to Equation 4:

Equation 4:

$$
\text { Removal }(\%)=\left(1-\frac{\text { Concentration last tank }(\boldsymbol{P})}{\text { Concentration initial tank }(\boldsymbol{H 0})}\right) \times 100
$$

For the degradation evaluation, a compound was considered degradable when the removal (\%) after the treatment train would be over $20 \%$. This assessment was based on an expanded uncertainty (measurements and experimental) of $\pm 10 \%$.

\section{Results and discussion}

\subsection{General Parameters for the treatment system}

The system had operated continuously for 10 months before the experiments were performed. All flows and set points of the system were kept constant for the last two months after which the experiments were performed. The parameters that characterise the general water treatment performance in this period are summed up in Table 1. 
Oxygen was never below $2.5 \mathrm{mg} / \mathrm{L}$ in H1 (sludge only system) and $4.5 \mathrm{mg} / \mathrm{L}$ in H2-H4 (biofilm and sludge) thus oxygen concentrations were high enough to support nitrification and aerobic biodegradation at the substrate concentrations in the reactors. In the the two-month period before the experiments the $\mathrm{pH}$ was stable between 7 and 8 except in the last reactor (MBBR).

Nitrification reached $80-90 \%$ already in H1 that only had sludge, and was complete in H2. This shows a high nitrification capacity in the sludge. Hybas ${ }^{\mathrm{TM}}$ systems are often designed with higher loading so the sludge mainly degrades organic material (BOD) but have too low sludge age to maintain a high nitrification capacity. Instead biofilm have high nitrifiers density as these bacteria are not washed out with the sludge growth. It can be concluded that the system was very low-loaded and likely a much higher ammonia load could have been treated.

In the experimental period the removal of most of the DOC and COD occurred in H1 which is consistent with the functional design of the system. In the next stages (H2 to P) a further reduction in both parameters is observed (See Table 1). From the COD in and out of the sludge tank H0 an operational $\mathrm{BOD}$ concentration $\mathrm{BOD}_{\mathrm{op}}$ can be assessed as $\mathrm{BOD}_{\mathrm{op}}=\mathrm{COD}$ in $-\mathrm{COD}$ out $=244 \mathrm{mg}$ $\mathrm{O} / \mathrm{L}$.

\subsection{Removal of Pharmaceuticals in the Hybas reactor}

The found removal rate constants of the pharmaceuticals were highest in the sludge reactor $(\mathrm{H} 1)$ during the batch experiment. In contrast, for the continuous flow experiments, the same reactor (H1) showed negative removals (production) for some compounds. Removals between 0 and $71 \%$ were observed for reactors $\mathrm{H} 2, \mathrm{H} 3$ and $\mathrm{P}$ (Figure 4). 


\subsubsection{Batch experiment}

Single phase first-order degradation kinetics (Equation 1) was fitted for each pharmaceutical in the respective reactors. However, for propranolol, a two-phase first order kinetics approach seemed to be a more appropriate fitting (Figure 2) than single phase first-order kinetics. Such fitting is better explained in the supplementary information S5. Figure 2 shows nine illustrative compounds while the degradation kinetics of the rest of the investigated compounds is shown in the supplementary material (S3).

From these kinetic data, removal rate constants were calculated from the batch experiments (Table 2).

\subsubsection{Continuous flow experiment}

The concentrations of pharmaceuticals during the continuous flow experiment are shown as the average concentrations in each reactor. Figure 3 shows nine illustrative compounds. The rest of the compounds are presented in the supplementary information (S4). Considering the 17 detected compounds in $\mathrm{H} 0,20 \%$ of each of 13 compounds was removed during the treatment.

During the continuous flow experiment most pharmaceuticals were removed. However, some pharmaceuticals presented low or negative removals (i.e. they were produced) (Figures 3 and 4). This is a phenomenon that can occur with compounds that are eliminated via urine or faeces in a conjugate form. Such conjugates are usually formed during phase II of human metabolism by sulfation, acetylation and glucuronidation to increase solubility and to facilitate excretion (Timbrell 2009). These excreted conjugates can undergo de-conjugation in the course of the sewer or during the wastewater treatment by bacterial enzymes. In this way effluent concentrations of the parent compound can be bigger than those in the influent. Another study also proposed that the increase of 
a parent compound could happen via transformation of metabolites from other parent compounds (Kovalova et al. 2012).

The rise of the amount of the parent pharmaceuticals in the effluent or at an intermittent treatment stage has formerly been observed in WWTPs (Ternes 1998, Onesios et al. 2009, Falås et al. 2012) and in hospital wastewater treatment plants (Kovalova et al. 2012, Cruz-Morató et al. 2014). This effect is expected to be even stronger in source treatment systems as hospital wastewater because the travel time of conjugates between the source and the treatment is much shorter than in the sewers that lead to municipal WWTPs. In Figure 4 the removal observed during the continuous flow experiment are compared to the calculated ones from the batch experiments. This comparison can be used to discern whether compounds could be potentially biodegraded and to understand each of the steps (reactors) in the treatment system.

The removals found in the batch experiment were comparable to the ones obtained in the continuous flow experiment. The difference in removal percentage between batch and experiment data corresponded to a standard deviation of $\pm 33 \%$. This fact indicates that such systems could be modelled with batch experimental data. On the other side, this study also pointed out how measuring inlet and outlet concentrations from treatment systems could hide the actual biodegradation process of compounds that are excreted as conjugates as in the case of the first reactor $(\mathrm{H} 1)$, where many compound removals were negative.

According to Equation 2 the removal over the series of reactors was assessed considering the batch reactors and compared to the removals found in the train during continuous flow. It was thus predicted that 16 out of 26 compounds were removed with more than $20 \%$ within the treatment system (Figure 4). From the $k_{i}$ values for the system, $k_{H 1}$ or $k_{H 3}$ were in general the highest removal rate constants (Table 2). The fact that $\mathrm{H} 3$ had a high removal rate constant was probably related to a fairly efficient biomass, even if total biomass in this reactor was less than in the other ones. As H1 
was the first reactor in the treatment train, most of the total removal was occurring there (Figure 4). When correcting the $k_{i}$ values with the amount of biomass per reactor volume $\left(k_{b i o}\right)$ the most efficient reactor appeared to be the polishing MBBR (P). This is an indication that $\mathrm{P}$ was actually highly adapted to remove micro-pollutants.

\subsection{Pharmaceuticals Removal: Trends}

Different trends were observed through the different compounds in terms of removal and degradation kinetics.

\subsubsection{Beta-blockers}

Beta-blockers (atenolol, metoprolol, propranolol and sotalol) could be degraded in the batch experiment. For atenolol (Supplementary information S2 and S 3, numerical data in Table 2) a removal close to $100 \%$ was determined while it was a bit over $20 \%$ for the other beta-blockers. During the continuous flow experiment atenolol, metoprolol and propranolol were detected in H0 and degraded later during the treatment train (Metoprolol and Propranolol in Figure 3). The degradation rates were fairly matching the estimated ones from the batch experiment.

Propranolol concentrations were higher in $\mathrm{H} 1$ in comparison to $\mathrm{H} 0$, such formation of propranolol was compensated later by the following reactors removal. This gave an apparent no-removal of propranolol when comparing inlet $(\mathrm{H} 0)$ and outlet $(\mathrm{P})$ concentrations during the continuous flow experiment (Figure 3). Propranolol is known to be the only beta-blocker forming conjugates (Documed 2014) and, furthermore it was degraded in the batch experiment. Therefore, this apparent no-removal was most likely the result of propranolol being formed by de-conjugation at a similar 
rate than it was being degraded. This finding would also be in agreement with a previous MBR study (Kovalova et al., 2012) that also observed negative removals of propranolol in hospital wastewater treatments operating at similar hydraulic retention times.

Remarkably, atenolol was removed better than the other three beta-blockers. Such high removals might be explained by co-metabolism. Unlike metoprolol and sotalol, the biodegradation of atenolol has been previously observed and linked to the activity of ammonia-oxidizing bacteria and heterotrophs (Sathyamoorthy et al., 2013). This hypothesis of co-metabolism fits the present study because, again, unlike metoprolol and sotalol, the degradation of atenolol occurs in parallel to ammonia oxidation (Table 2). The removal of atenolol from wastewater has also shown to be higher than the removal for other beta-blockers in previous studies on hospital wastewater treatment (Nielsen et al., 2013,).

The degradation of propranolol, metoprolol and sotalol occurred in different tanks than the nitrification. This points out that nitrification and degradation of beta-blockers (except perhaps atenolol) are independent processes. On the other side, the the removal of atenolol, coinciding with nitrification.

\subsubsection{Iodinated X-ray Contrast Media (ICM)}

Iopamidol, iohexol and iomeprol could be degraded following first-order kinetics (Figure 2, supplementary material, S2 and S3, numerical data in Table 2), with both, estimated and real removal between 60 and 80\% (Figure 4). Iopromid and diatrizoic acid were not removed. ICM are not metabolized or conjugated in humans (Bourin et al., 1997). Therefore the fact that the data for 
ICMs from the batch experiment matches the continuous flow results better than most other groups of pharmaceuticals investigated might be due to the lack of de-conjugation processes. Slow sand-filtration biofilm reactors were able to degrade ICM (Escolà Casas and Bester 2015). Also, MBBR were shown to degrade iohexol and diatrizoic acid from wastewater (Hapeshi et al., 2013). As the hydraulic retention time in the present study was similar to Kovalova et al., (2012), it seems that the key to degrade ICM is more likely to rely on the biomass characteristics. In this case the determining factor appears to be the presence of different types of biofilm in the treatment system that are the common factor (Escolà Casas and Bester 2015; Hapeshi et al., 2013; this study). In this study biodegradation was detected in the sludge-only reactor (H1). This result is supporting the theory that degradation of ICM is not necessarily only occurring in biofilms but can possibly also be performed by sludge organisms. However, selection of microorganisms that grow up in the biofilm and seed the sludge might also be of importance. The fact that the system is very low loaded in BOD gives a low sludge production and thus the possibility for slow growing microorganisms to survive in the sludge without being washed out.

Iohexol, iomeprol and iopamidol presented the highest $k_{b i o}$ in $\mathrm{H} 1$ ( $k_{\mathrm{H} 1 b i o}$ in table 2$)$, which contained only sludge, and the lowest $k_{\text {bio }}$ in $\mathrm{P}$, which contained only MBBR. The $k_{b i o}$ values in $\mathrm{H} 2$ and $\mathrm{H} 3\left(k_{\mathrm{H} 2 \mathrm{bio}}\right.$ and $k_{\mathrm{H} 3 \mathrm{bio}}$ in table 2$)$ were lower but close to the $\mathrm{H} 1$ value. Since the main part of biomass in these two tanks was mainly consisting of recirculated sludge from $\mathrm{H} 3$ to $\mathrm{H} 1$, it makes sense that such values do not differ so much from each other (Tables 1 and 2). According to the $k_{b i o}$ values, it seems that in this set-up, the sludge biomass community was more efficient in removing ICM than the MBBR community.

ICM are usually persistent to conventional WWTP treatment as well as realistic ozone treatment (Kovalova et al., 2012, Hapeshi et al., 2013). MBR treatment showed negligible removals of ICM from hospital wastewater, except for iopromide which was removed up to $31 \%$ (Kovalova et al., 
2012). Also other hospital wastewater-treatment studies employing MBR (Nielsen et al., 2013) or fungal fluidized-bed bioreactor in non-sterile conditions (Cruz-Morató et al., 2014) found low removal (ranging from 0 and 44\%) for ICM. The direct degradation of the three X-ray contrast media by the present treatment train can position Hybas ${ }^{\mathrm{TM}}$ technology as a solution to remove this kind of compounds.

\subsubsection{Sulfonamides}

Sulfadiazine, sulfamethoxazole and sulfamethizole as well as the sulfadiazine metabolite (acetylsulfadiazine) are a group related structures (supplementary information, S1) that behaved differently during the wastewater treatment.

During the batch experiment, the concentration of sulfadiazine decreased in $\mathrm{H} 1, \mathrm{H} 2$ and $\mathrm{H} 3$ reactors, while it remained stabled in reactor P. Acetyl-sulfadiazine, its main metabolite, seemed to follow the same pattern, degrading fairly fast also in $\mathrm{H} 1, \mathrm{H} 2$ and $\mathrm{H} 3$ but not in P. Sulfadiazine is mainly conjugated to acetyl-sulfadiazine in humans and excreted as such (Vree et al., 1995). In the batch experiments, sulfadiazine and acetyl-sulfadiazine were added, so the de-conjugation of sulfadiazine and formation of acetyl-sulfadiazine could not be observed. Instead, it was observed that both compounds can be degraded in the Hybas ${ }^{\mathrm{TM}}$ set-up.

In the continuous flow experiment sulfadiazine concentrations remained stable, while the concentration of acetyl-sulfadiazine increased by $0.6 \mu \mathrm{g} \mathrm{L}^{-1}$ (Figure 3). Thus, the expectations that acetyl-sulfadiazine would de-conjugate to form sulfadiazine were not fulfilled. This suggests that other interactions might occur between sulfadiazine and sulfadiazine metabolites. 
The batch experiment showed that both, sulfamethoxazole and sulfamethizole could be degraded by the treatment system (Figure 2 and supplementary information S3). In humans, sulfamethoxazole is usually also excreted in acetylated form while sulfamethizole is only acetylated in small amounts (3\%) (Hekster and Vree 1982). When operating the system at continuous flow, $25 \%$ of sulfamethizole was removed while the other three sulfonamide concentrations appeared to increase or stay stable. This is comparable to the results obtained with an MBR by Kovalova et al., (2012) but different from Nielsen et al., (2013) who found almost complete removal of sulfonamides by an MBR treatment.

Therefore an explanation for stable concentrations of sulfamethoxazole during the continuous flow experiment (Figure 3) could be due to the fact that de-conjugation of acetyl-sulfamethoxazole and degradation of sulfamethoxazole would happen at similar rate constants. De-conjugation of acetylsulfamethoxazole has already been observed in previous studies (, Köhler et al., 2012, Kovalova et al., 2012) as well as during studies on municipal WWTPs (Onesios et al., 2009).

Finally, sulfamethizole concentrations diminished by circa $0.7 \mu \mathrm{g} \mathrm{L}$. The calculated removal of sulfamethizole matched well the experimental removal during the continuous flow experiment. This was expected as this compound is not excreted as an acetylated conjugate.

\subsubsection{Analgesics}

During the batch experiment, phenazone concentrations decreased following first order kinetics but the overall removal was under $20 \%$.. In the present study the pure MBBR reactor (P) showed to be the one with the lowest removal. This finding might indicate that the degradation of phenazone is a co-metabolic process. Phenazone was not detected during the continuous flow experiment. 
In the batch experiments the concentrations of tramadol were decreasing but the removal calculated with the resulting reaction rate constants was below $20 \%$ (not significant). The removal determined during the continuous flow experiment agreed to this calcultaion. However, during the batch experiment the removal rate constant of tramadol was the lowest in reactor $\mathrm{P}$ while during the continuous flow experiment reactor $\mathrm{P}$ was more effective in removing tramadol. In the previous study, on pure MBBR operations, tramadol could not be removed. Also Kovalova et al., (2012) found that tramadol was not degraded in an MBR.

Diclofenac did not degrade in the batch experiment.. The degradation data of diclofenac is inconsistent, showing degradation in some systems and to be recalcitrant in others (Onesios et al., 2009). Further studies regarding the degradation conditions for diclofenac should be conducted in the future.

\subsubsection{Antidepressants/Antiepileptic}

For batch and continuous flow experiments, venlafaxine removal was under $20 \%$. Previously described treatment systems (Nielsen et al., 2013, Kovalova et al., 2012) and data from municipal WWTPs (Metcalfe et al., 2010) also described poor removal for this compound.

The removal of carbamazepine was calculated to be close to $20 \%$ during the batch. This concentration decrease only occurred in the $\mathrm{P}$ reactor during the continuous flow experiment. A previous project operating MBBR reactors in series showed similar results for carbamazepine. The fact that carbamazepine could be degraded by this MBBR is a small success as carbamazepine is usually a very recalcitrant compound in activated sludge WWTP and it has not been degraded in 
other hospital wastewater-treatment projects (Nielsen et al., 2013, Kovalova et al., 2012, Falås et al., 2013, Onesios et al., 2009).

In the batch experiment citalopram was removed up to a bit less than $20 \%$ while during the continuous flow experiment the concentration of this compound increased during the H1 treatment, stayed stable through $\mathrm{H} 2$ and $\mathrm{H} 3$ and then decreased during its pass through the $\mathrm{P}$ reactor. In a previous experiment using MBBR reactors in series citalopram was degraded during the batch experiment but it remained stable during the continuous flow experiment. No removal of citalopram was also observed in similar projects and WWTPs (Nielsen et al., 2013, Metcalfe et al., 2010). The increase of citalopram concentrations in $\mathrm{H} 1$ might be due to de-conjugation or formation from other metabolites. Such citalopram concentrations were attenuated during through the passage of the $\mathrm{P}$ reactor.

\subsubsection{Macrolides and other antibiotics}

The removals of the macrolides erythromycin, clindamycin and clarithromycin were estimated from the batch experiments and found to range from 30 to $55 \%$ while azithromycin did not degrade. For these compounds, the removals in continuous flow experiments were around $40 \%$ for erythromycin and close to $100 \%$ for clindamycin. This data is to some extent in agreement with the previous studies by Kovalova et al., (2012) who reported macrolides removals by an MBR between 20 to $60 \%$. Concerning clindamycin, in two prior studies, it was formed rather than eliminated (Nielsen et al., 2013, Kovalova et al., 2012). In contrast, in the present study, clindamycin degraded in both, the batch and continuous flow experiments. The key to understand the results discrepancy with 
previous literature might rely on the sludge/biofilm characteristics of the system that, somehow, developed efficient clindamycin degraders.

Regarding other antibiotics, ciprofloxacin was not degraded as reported in Kovalova et al., (2012) and Nielsen et al., (2013), where ciprofloxacin degraded 50 and $36 \%$ respectively in the MBR. The estimated removal of trimethoprim from the first-order kinetics of batch experiments was a bit over $20 \%$, which agrees well with the removal found in the continuous flow experiment (Figure 2). Trimethoprim was produced in H1 but degraded during the following steps of the treatment train.

\section{Conclusion}

A train of four reactors combining sludge, Hybas $^{\mathrm{TM}}$ and a polishing MBBR reached similar or better removal efficiencies of pharmaceuticals compared to other technologies (i.e activated sludge or MBR), particularly when considering specific compounds (like X-ray contrast media).

The degradation of organic matter and nitrification mainly occurred in the first treatment reactor indicating that the system was a low loaded one compared to the systems for treating general wastewater. In addition, Hybas ${ }^{\mathrm{TM}}$ also reached low organic matter values in the outlet through a consistent (but small) stepwise removal in the following treatment steps which maintains a low loaded biofilm adapted for growing on hardly degradable organic matter. This process results in an effluent which is low in DOC and thus more suitable for a cost effective polishing by ozonation (Antoniou, 2013).

The batch experiment helped to assess the potential biodegradation of pharmaceuticals in the systems whereas the continuous flow experiment reported actual performance values. Batch and continuous flow experimental results matched for several compounds, especially those that are excreted unchanged. This means that de-conjugation, bonding to particles or formations from other 


\section{Acknowledgments}

The authors want to acknowledge the AUFF grant "Advanced water purification using bioinorganic nanocatalysts and soil filters" (http://waterpurification.au.dk/) and the MERMISS project (Miljøeffektiv rensning af højpotente lægemiddelstoffer i hospitalsspildevand - Environmentally effective removal of pharmaceuticals from hospital wastewater) with all its co-founding, active and supporting partners. The authors are also grateful to Kim Sundmark and the rest of the operation team for the support in operating the pilot plant. 


\section{References}

Bester, K. and Schafer, D. (2009) Activated soil filters (bio filters) for the elimination of xenobiotics (micro-pollutants) from storm- and waste waters. Water Research 43, 2639-2646.

Christensson M. and Welander T. (2004). Treatment of municipal wastewater in a hybrid process using a new suspended carrier with large surface area. Water Science and Technol., 49, 207-214.

Cruz-Morató, C., Lucas, D., Llorca, M., Rodriguez-Mozaz, S., Gorga, M., Petrovic, M., Barceló, D., Vicent, T., Sarrà, M. and Marco-Urrea, E. (2014) Hospital wastewater treatment by fungal bioreactor: Removal efficiency for pharmaceuticals and endocrine disruptor compounds. Science of The Total Environment 493, 365-376.

Debabrata M. (2010) Removal of high organics containing wastewater in a shaft-type activated sludge hybrid reactor. International Journal of Environmental Sciences, 1, 368-382.

Escolà Casas, M. and Bester, K. (2015) Can those organic micro-pollutants that are recalcitrant in activated sludge treatment be removed from wastewater by biofilm reactors (slow sand filters)? Science of The Total Environment 506-507, 315-322.

Escolà Casas,M., Ravi Kumar Chhetri, Gordon Ooi, Kamilla M. S. Hansen, Klaus Litty, Magnus Christensson, Caroline Kragelund, Henrik R. Andersen and Kai Bester: Biodegradation of pharmaceuticals in hospital wastewater by staged Moving Bed Biofilm Reactors (MBBR), Water Research, submitted, 2015

Falås, P., Baillon-Dhumez, A., Andersen, H.R., Ledin, A. and la Cour Jansen, J. (2012) Suspended biofilm carrier and activated sludge removal of acidic pharmaceuticals. Water Research 46, 11671175.

Falås, P., Longrée, P., la Cour Jansen, J., Siegrist, H., Hollender, J. and Joss, A. (2013) Micropollutant removal by attached and suspended growth in a hybrid biofilm-activated sludge process. Water Research 47, 4498-4506.

Hapeshi, E., Lambrianides, A., Koutsoftas, P., Kastanos, E., Michael, C. and Fatta-Kassinos, D. (2013) Investigating the fate of iodinated X-ray contrast media iohexol and diatrizoate during microbial degradation in an MBBR system treating urban wastewater. Environ Sci Pollut Res Int. 20,3592-3606.

Heberer, T., Mechlinski, A., Fanck, B., Knappe, A., Massmann, G., Pekdeger, A. and Fritz, B. (2004) Field studies on the fate and transport of pharmaceutical residues in bank filtration. Ground Water Monitoring and Remediation 24, 70-77. 
Hekster, C.A. and Vree, T.B. (1982) Clinical pharmacokinetics of sulphonamides and their N4acetyl derivatives. Antibiot Chemother (1971) 31, 22-118.

Hijosa-Valsero, M., Matamoros, V., Sidrach-Cardona, R., Pedescoll, A., Martin-Villacorta, J., Garcia, J., Bayona, J.M. and Becares, E. (2011) Influence of design, physico-chemical and environmental parameters on pharmaceuticals and fragrances removal by constructed wetlands. Water Science and Technology 63, 2527-2534.

Janzen, N., Banzhaf, S., Scheytt, T. and Bester, K. (2009) Vertical flow soil filter for the elimination of micro pollutants from storm and waste water. Chemosphere 77, 1358-1365.

Joss, A., Siegrist, H. and Ternes, T.A. (2008) Are we about to upgrade wastewater treatment for removing organic micropollutants? Water Science and Technology 57, 251-255.

Joss, A., Zabczynski, S., Gobel, A., Hoffmann, B., Loffler, D., McArdell, C.S., Ternes, T.A., Thomsen, A. and Siegrist, H. (2006) Biological degradation of pharmaceuticals in municipal wastewater treatment: Proposing a classification scheme. Water Research 40, 1686-1696.

Ødegaard, H., Christensson, M. \& Sørensen, K. 2014 Hybrid systems. In: Activated Sludge- 100 Years and Counting. (Jenkins, D. \& Wanner, J., eds). IWA Publishing.

Köhler, C., Venditti, S., Igos, E., Klepiszewski, K., Benetto, E. and Cornelissen, A. (2012) Elimination of pharmaceutical residues in biologically pre-treated hospital wastewater using advanced UV irradiation technology: A comparative assessment. Journal of Hazardous Materials 239-240, 70-77.

Kosma, C.I., Lambropoulou, D.A. and Albanis, T.A. (2010) Occurrence and removal of PPCPs in municipal and hospital wastewaters in Greece. Journal of Hazardous Materials 179, 804-817.

Kovalova, L., Siegrist, H., von Gunten, U., Eugster, J., Hagenbuch, M., Wittmer, A., Moser, R. and McArdell, C.S. (2013) Elimination of Micropollutants during Post-Treatment of Hospital Wastewater with Powdered Activated Carbon, Ozone, and UV. Environmental Science \& Technology 47, 7899-7908.

Kovalova, L., Siegrist, H., Singer, H., Wittmer, A. and McArdell, C.S. (2012) Hospital wastewater treatment by membrane bioreactor: performance and efficiency for organic micropollutant elimination. Environmental Science \& Technology 46, 1536-1545.

Li, D., Alidina, M. and Drewes, J.E. (2014) Role of primary substrate composition on microbial community structure and function and trace organic chemical attenuation in managed aquifer recharge systems. Applied Microbiology and Biotechnology, 98, 5747-5756. 
Liu, Q., Zhou, Y., Chen, L. and Zheng, X. (2010) Application of MBR for hospital wastewater treatment in China. Desalination 250, 605-608.

Mazumder, D. (2010) Removal of high organics containing wastewater in a shafttype activated sludge hybrid reactor. International Journal of Environmental Sciences 1, 368-382.

Metcalfe, C.D., Chu, S., Judt, C., Li, H., Oakes, K.D., Servos, M.R. and Andrews, D.M. (2010) Antidepressants and their metabolites in municipal wastewater, and downstream exposure in an urban watershed. Environmental Toxicology and Chemistry, 29, 79-89.

Nielsen, U., Hastrup, C., Klausen, M.M., Pedersen, B.M., Kristensen, G.H., Jansen, J.L., Bak, S.N. and Tuerk, J. (2013) Removal of APIs and bacteria from hospital wastewater by MBR plus O(3), $\mathrm{O}(3)+\mathrm{H}(2) \mathrm{O}(2)$, PAC or $\mathrm{ClO}(2)$. Water Science and Technology, 67, 854-862.

Onesios, K., Yu, J. and Bouwer, E. (2009) Biodegradation and removal of pharmaceuticals and personal care products in treatment systems: a review. Biodegradation, 20, 441-466.

Pauwels, B. and Verstraete, W. (2006) The treatment of hospital wastewater: an appraisal. Journal of Water Health 4, 405-416.

Pills, P. (2012) Pills Project: Pharmaceutical residues in the aquatic system- a challenge for the future. A European partnership project of: Emschergenossenschaft (DE), Waterschap Groot Salland (NL), Centre de Recherche Public Henri Tudor (LU), Eawag (CH), Glasgow Caledonian University (UK) and Université de Limoges (FR). http://www.pillsproject.eu/content/136/documents/PillsBrochure-en.pdf Randall, C.W. and Sen, D. (1996) Full-scale evaluation of an integrated fixed-film activated sludge (IFAS) process for enhanced nitrogen removal. Water Science and Technology 33, 155-162.

Reungoat, J., Escher, B.I., Macova, M. and Keller, J. (2011) Biofiltration of wastewater treatment plant effluent: Effective removal of pharmaceuticals and personal care products and reduction of toxicity. Water Research 45, 2751-2762.

Santos, L.H.M.L.M., Gros, M., Rodriguez-Mozaz, S., Delerue-Matos, C., Pena, A., Barceló, D. and Montenegro, M.C.B.S.M. (2013) Contribution of hospital effluents to the load of pharmaceuticals in urban wastewaters: Identification of ecologically relevant pharmaceuticals. Science of The Total Environment 461-462, 302-316.

Sathyamoorthy, S., Chandran, K. and Ramsburg, C.A. (2013) Biodegradation and Cometabolic Modeling of Selected Beta Blockers during Ammonia Oxidation. Environmental Science \& Technology 47, 12835-12843. 
Thomas, K.V., Dye, C., Schlabach, M. and Langford, K.H. (2007) Source to sink tracking of selected human pharmaceuticals from two Oslo city hospitals and a wastewater treatment works. Journal of Environmental Monitoring, 9, 1410-1418.

Ternes, T.A., Joss, A. and Siegrist, H. (2004) Scrutinizing pharmaceuticals and personal care products in wastewater treatment. Environmental Science \& Technology 38, 392A-399A.

Verlicchi, P., Galletti, A., Petrovic, M. and Barceló, D. (2010) Hospital effluents as a source of emerging pollutants: An overview of micropollutants and sustainable treatment options. Journal of Hydrology 389, 416-428.

Verlicchi, P., AlAukidy, M., Zambello E. (2015) What have we learned fromworldwide experiences on the management and treatment of hospital effluent? - An overview and a discussion on perspectives, Science of the Total Environment 514, 467-491.

Zearley, T.L. and Summers, R.S. (2012) Removal of Trace Organic Micropollutants by Drinking Water Biological Filters. Environmental Science \& Technology 46, 9412-9419.

Zupanc, M., Kosjek, T., Petkovšek, M., Dular, M., Kompare, B., Širok, B., Blažeka, Ž. and Heath, E. (2013) Removal of pharmaceuticals from wastewater by biological processes, hydrodynamic cavitation and UV treatment. Ultrasonics Sonochemistry 20, 1104-1112. 
Table 1: General parameters \pm standard deviation for the Hybas ${ }^{\mathrm{TM}}$ system during a two months period including the sampling for both experiments.

\begin{tabular}{|c|c|c|c|c|c|c|c|c|c|c|}
\hline \multirow[t]{3}{*}{ Reactor } & \multirow[t]{3}{*}{ HRT } & \multicolumn{3}{|c|}{ Biomass } & \multirow[t]{3}{*}{$\mathrm{pH}$} & \multirow{3}{*}{$\begin{array}{c}\text { DOC } \\
{[\mathrm{mgC/L}]}\end{array}$} & \multirow{3}{*}{$\begin{array}{c}\text { COD } \\
\text { [mgO/L] }\end{array}$} & \multirow{3}{*}{$\begin{array}{c}\mathrm{NH}_{4}{ }^{+}-\mathbf{N} \\
{[\mathrm{mgN} / \mathrm{L}]}\end{array}$} & \multirow{3}{*}{$\begin{array}{l}\mathrm{NO}_{2}{ }^{-} \mathrm{N} \\
{[\mathrm{mgN} / \mathrm{L}]}\end{array}$} & \multirow{3}{*}{$\begin{array}{c}\mathrm{NO}_{3}{ }^{-}-\mathrm{N} \\
{[\mathrm{mgN} / \mathrm{L}]}\end{array}$} \\
\hline & & \multirow{2}{*}{$\begin{array}{c}\text { Sludge } \\
\text { [g/L] }\end{array}$} & \multicolumn{2}{|c|}{ Carriers } & & & & & & \\
\hline & & & {$\left[\mathrm{g} / \mathrm{m}^{2}\right]$} & {$[\mathrm{g} / \mathrm{L}]$} & & & & & & \\
\hline $\mathrm{HO}$ & - & 0.17 & - & - & $7.6 \pm 0.28$ & $59 \pm 27$ & $299 \pm 209$ & $54 \pm 16$ & $0.12 \pm 0.13$ & $1.7 \pm 1.3$ \\
\hline $\mathrm{H} 1$ & 3 & 3.12 & - & - & $7.4 \pm 0.24$ & $15 \pm 3$ & $55 \pm 3$ & $7 \pm 6$ & $0.97 \pm 1.32$ & $50 \pm 7$ \\
\hline $\mathrm{H} 2$ & 3 & 3.12 & 6.0 & 2.4 & $7.3 \pm 0.42$ & $16 \pm 1$ & $50 \pm 10$ & $0.30 \pm 0.16$ & $0.06 \pm 0.04$ & $56 \pm 5$ \\
\hline $\mathrm{H} 3$ & 3 & 3.12 & 1.9 & 0.8 & $7.4 \pm 0.52$ & $14 \pm 2$ & $49 \pm 8$ & $0.06 \pm 0.05$ & $0.03 \pm 0.02$ & $60 \pm 9$ \\
\hline $\mathrm{P}$ & 3 & 0.04 & 2.5 & 1.0 & $7.8 \pm 0.48$ & $12 \pm 3$ & $43 \pm 12$ & $0.60 \pm 0.74$ & $0.02 \pm 0.01$ & $49 \pm 14$ \\
\hline
\end{tabular}

HRT= Hydraulic retention time [h] 


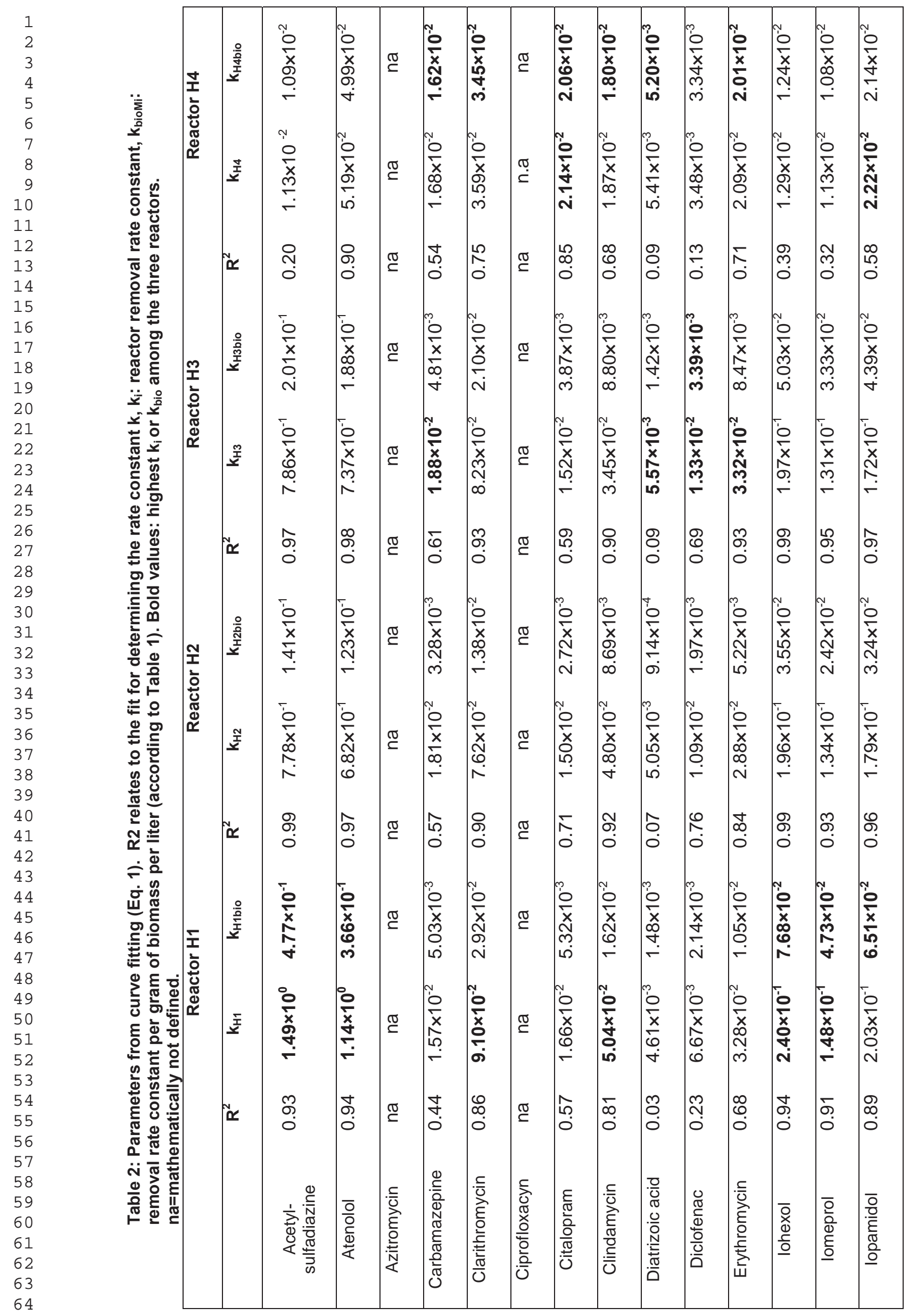




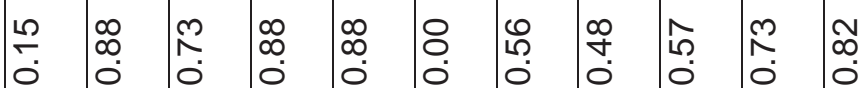

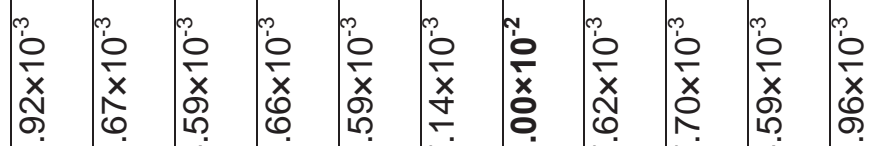

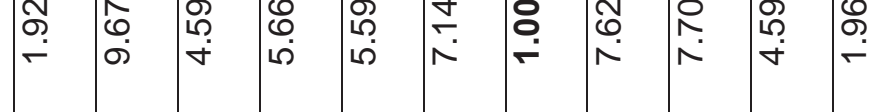

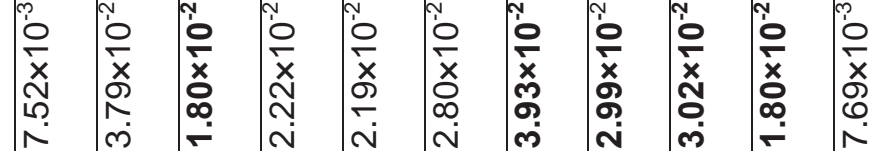

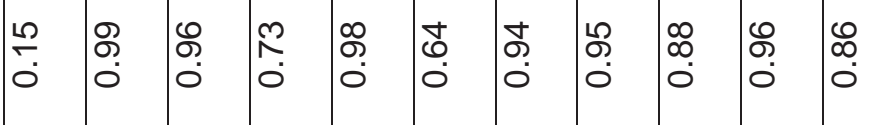

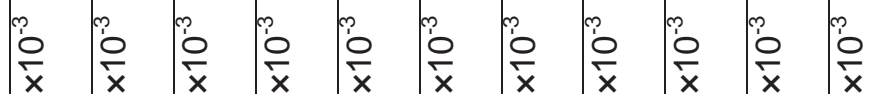

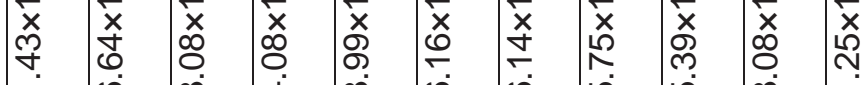

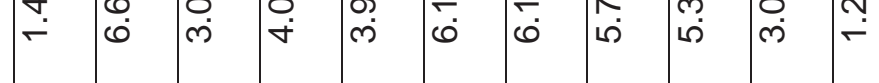

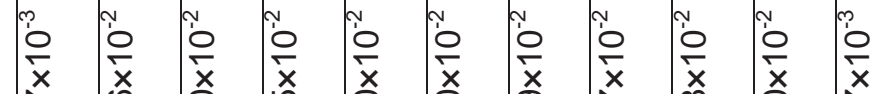

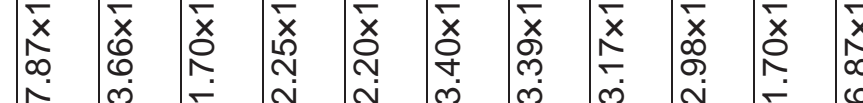

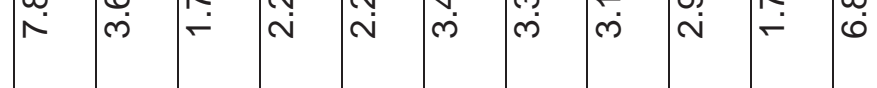

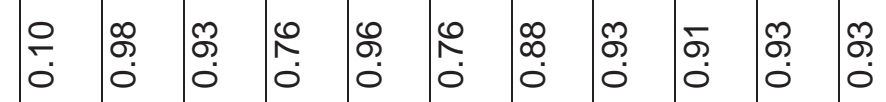

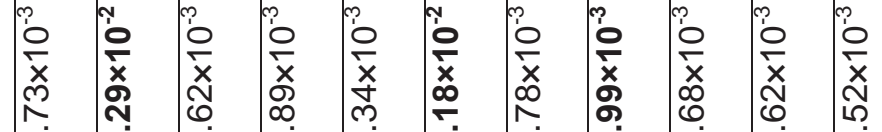

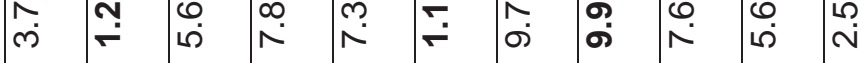

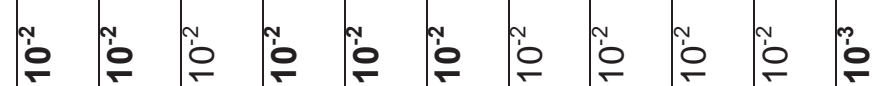

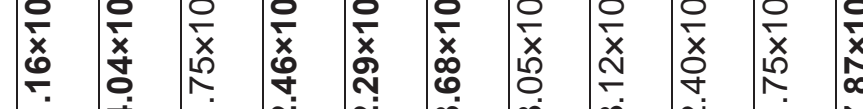

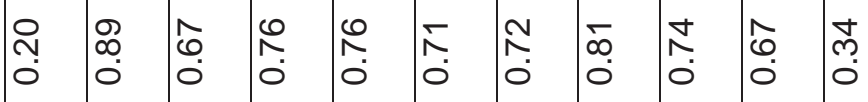

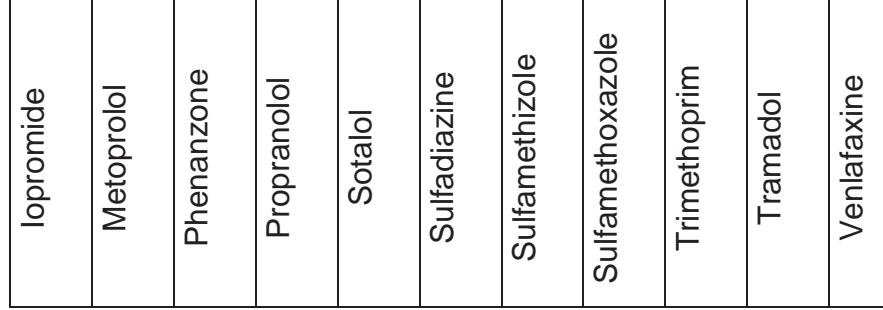


Figure 1: Overview of the pilot plant in Aarhus University Hospital.

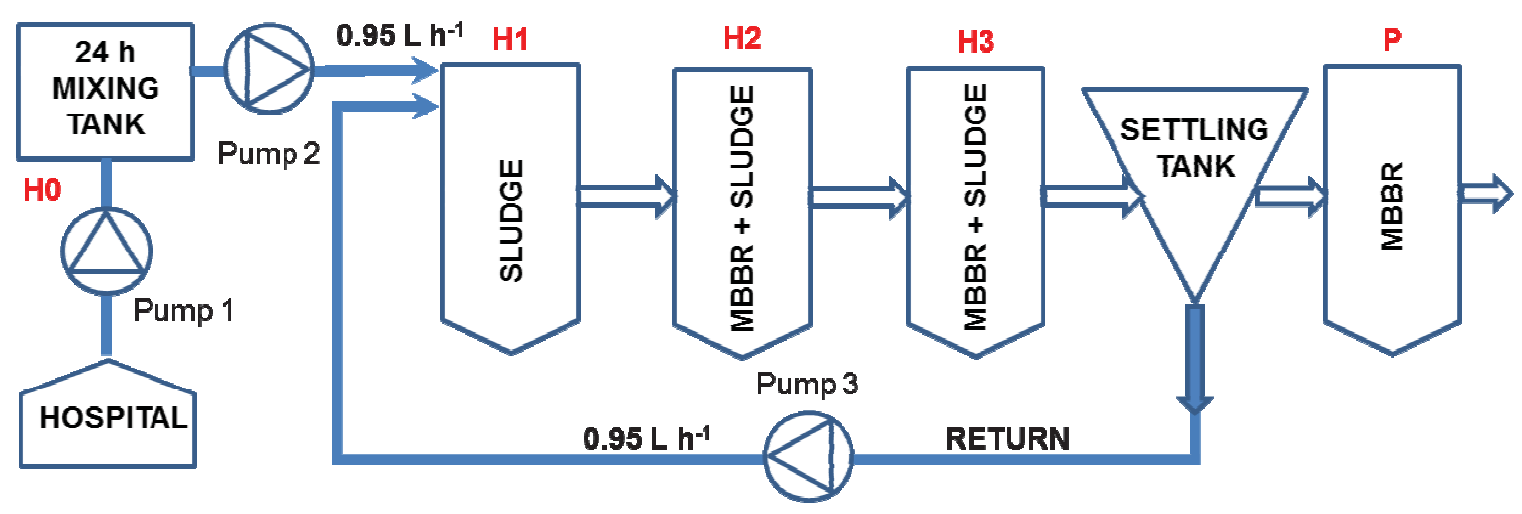


Figure 2: Concentrations of selected pharmaceuticals during the batch experiment in each reactor (H1, H2, H3 and P). Filled lines correspond to a first-order kinetics fitting (Equation 1).
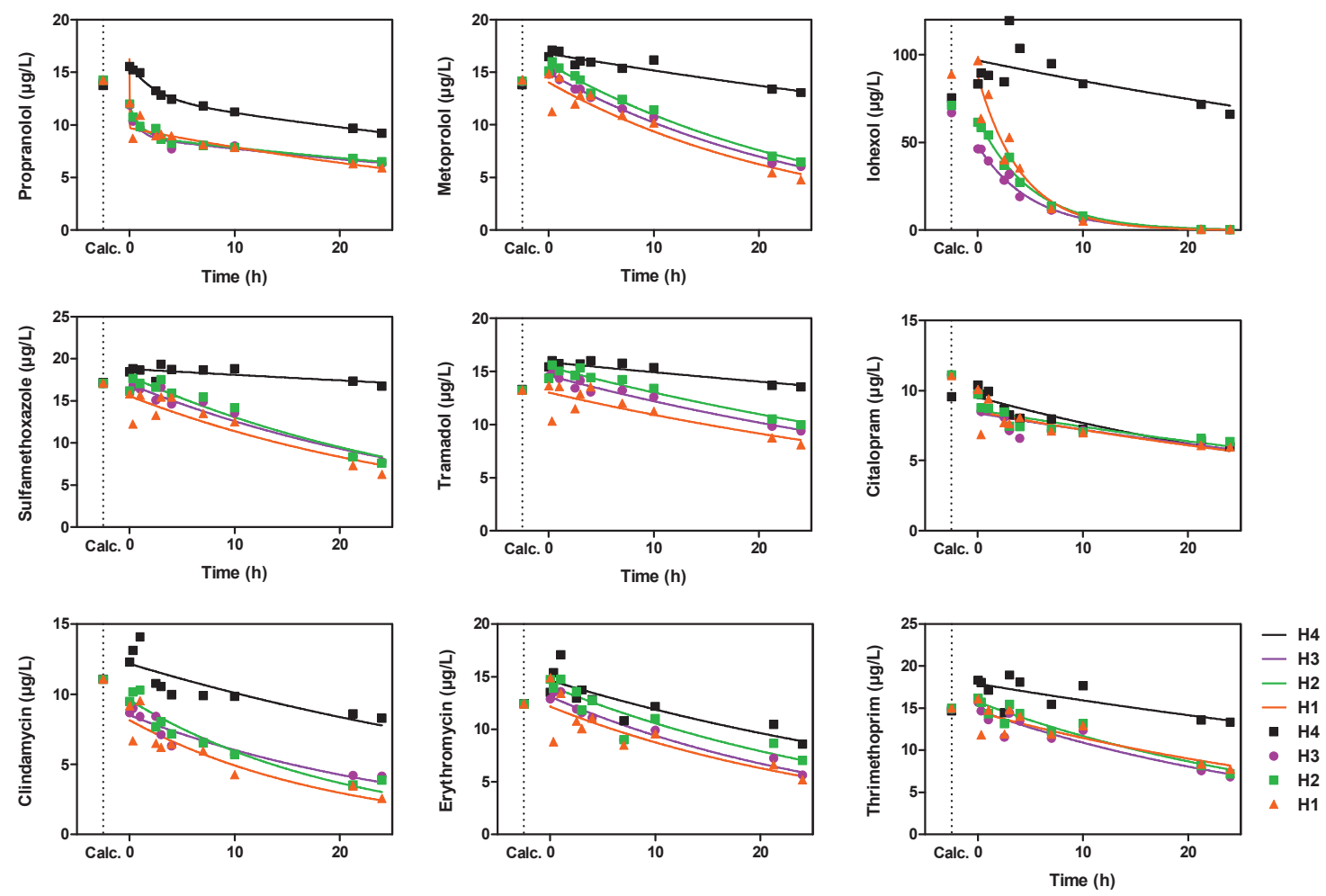
Figure 3: Average concentrations for selected compounds in the reactors during the continuous flow experiment. The error bars show the SD ( $n=2$ samples for $\mathrm{HO}$ and $n=4$ for the rest, each sample was analysed twice. SD was then derived from 4 measurements in $\mathrm{HO}$ and 8 measurements in the rest of the tanks).
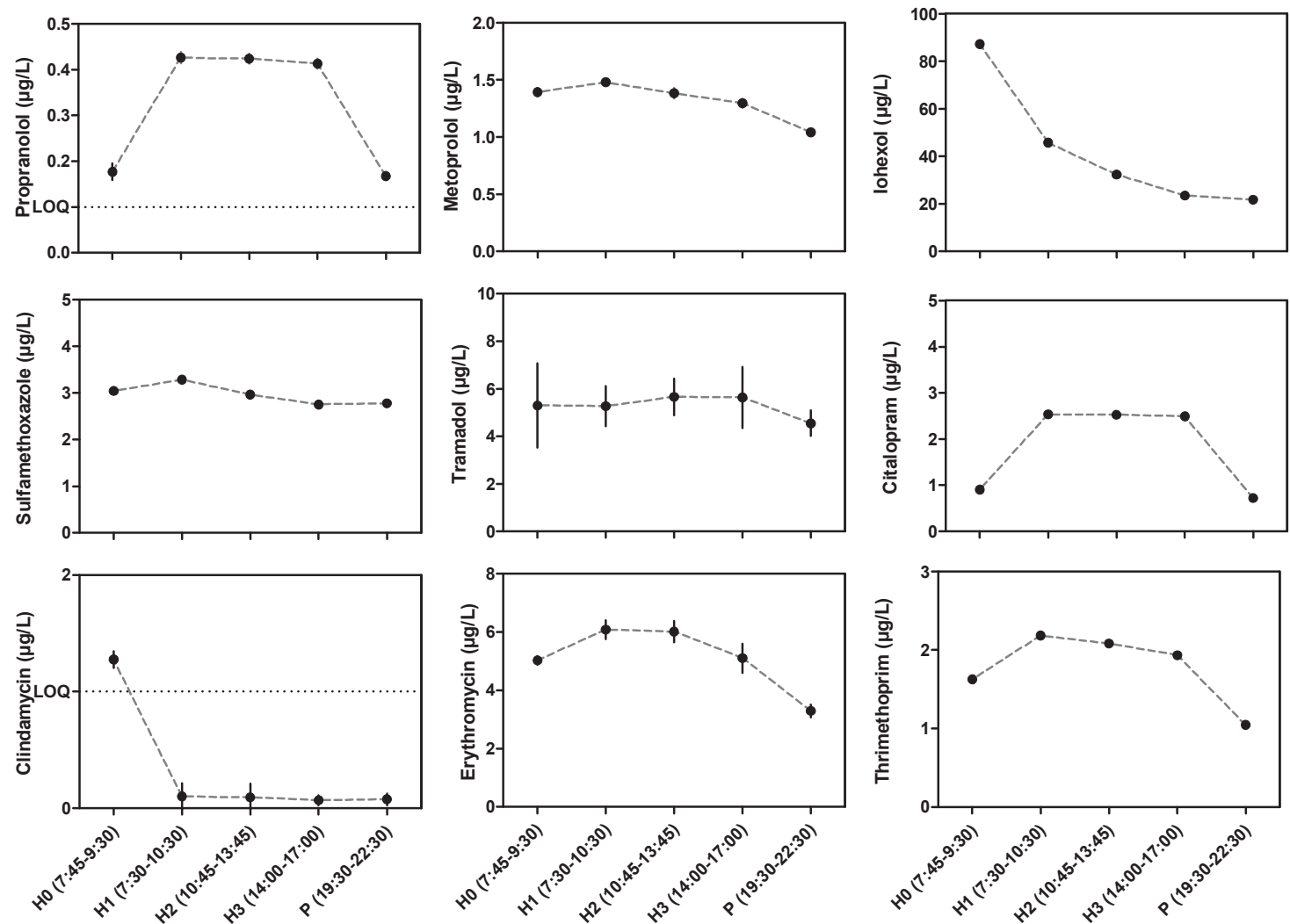
Figure 4: Removal estimated from the batch experiment (Equation 2) compared to the measured removal in the continuous flow experiment by applying Equation 4. *Known to be excreted as conjugates, **known metabolites ${ }^{* * *}$ suggested to be formed from metabolites of other compounds (Kovalova et al. 2012), ${ }^{* * *}$ suggested to be bound to faecal particles (Göbel et al. 2007).
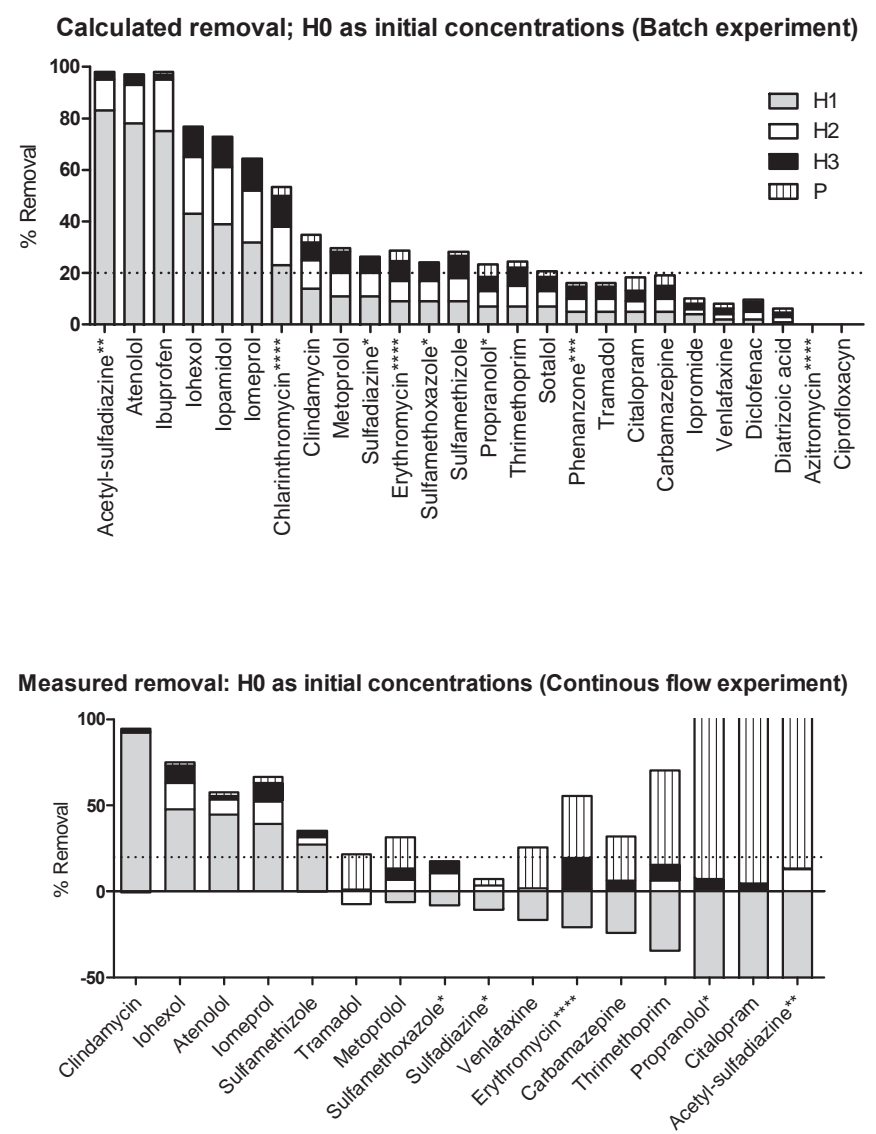

Measured removal; $\mathrm{H} 1$ as initial concentrations (Continous flow experiment)

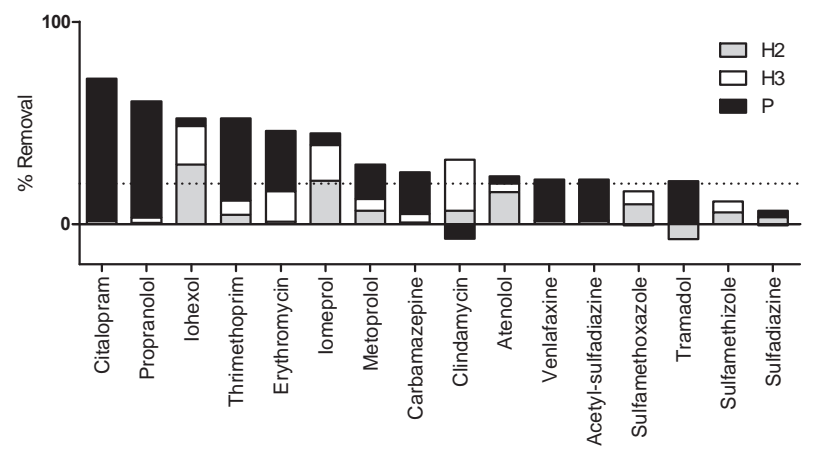


Click here to download Table: Tables_R2.docx

Table 1: General parameters \pm standard deviation for the Hybas ${ }^{\mathrm{TM}}$ system during a two months period including the sampling for both experiments.

\begin{tabular}{|c|c|c|c|c|c|c|c|c|c|c|}
\hline \multirow[t]{3}{*}{ Reactor } & \multirow[t]{3}{*}{ HRT } & \multicolumn{3}{|c|}{ Biomass } & \multirow[t]{3}{*}{$\mathrm{pH}$} & \multirow{3}{*}{$\begin{array}{c}\text { DOC } \\
{[\mathrm{mgC} / \mathrm{L}]}\end{array}$} & \multirow{3}{*}{$\begin{array}{c}\text { COD } \\
\text { [mgO/L] }\end{array}$} & \multirow{3}{*}{$\begin{array}{l}\mathrm{NH}_{4}^{+}-\mathbf{N} \\
{[\mathrm{mgN} / \mathrm{L}]}\end{array}$} & \multirow{3}{*}{$\begin{array}{c}\mathrm{NO}_{2}{ }^{-} \mathrm{N} \\
{[\mathrm{mgN} / \mathrm{L}]}\end{array}$} & \multirow{3}{*}{$\begin{array}{c}\mathrm{NO}_{3}{ }^{-} \mathrm{N} \\
{[\mathrm{mgN} / \mathrm{L}]}\end{array}$} \\
\hline & & \multirow{2}{*}{$\begin{array}{c}\text { Sludge } \\
\text { [g/L] }\end{array}$} & \multicolumn{2}{|c|}{ Carriers } & & & & & & \\
\hline & & & {$\left[\mathrm{g} / \mathrm{m}^{2}\right]$} & {$[\mathrm{g} / \mathrm{L}]$} & & & & & & \\
\hline $\mathrm{HO}$ & - & 0.17 & - & - & $7.6 \pm 0.28$ & $59 \pm 27$ & $299 \pm 209$ & $54 \pm 16$ & $0.12 \pm 0.13$ & $1.7 \pm 1.3$ \\
\hline $\mathrm{H} 1$ & 3 & 3.12 & - & - & $7.4 \pm 0.24$ & $15 \pm 3$ & $55 \pm 3$ & $7 \pm 6$ & $0.97 \pm 1.32$ & $50 \pm 7$ \\
\hline $\mathrm{H} 2$ & 3 & 3.12 & 6.0 & 2.4 & $7.3 \pm 0.42$ & $16 \pm 1$ & $50 \pm 10$ & $0.30 \pm 0.16$ & $0.06 \pm 0.04$ & $56 \pm 5$ \\
\hline H3 & 3 & 3.12 & 1.9 & 0.8 & $7.4 \pm 0.52$ & $14 \pm 2$ & $49 \pm 8$ & $0.06 \pm 0.05$ & $0.03 \pm 0.02$ & $60 \pm 9$ \\
\hline $\mathrm{P}$ & 3 & 0.04 & 2.5 & 1.0 & $7.8 \pm 0.48$ & $12 \pm 3$ & $43 \pm 12$ & $0.60 \pm 0.74$ & $0.02 \pm 0.01$ & $49 \pm 14$ \\
\hline
\end{tabular}

HRT= Hydraulic retention time [h] 


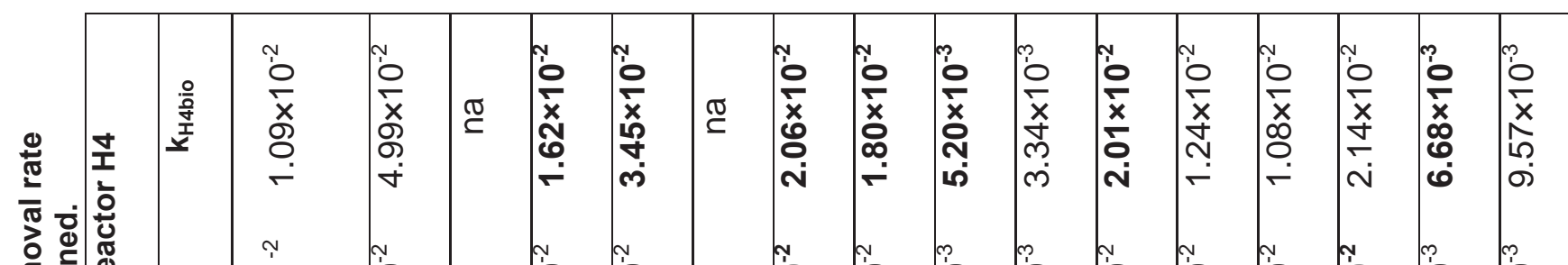

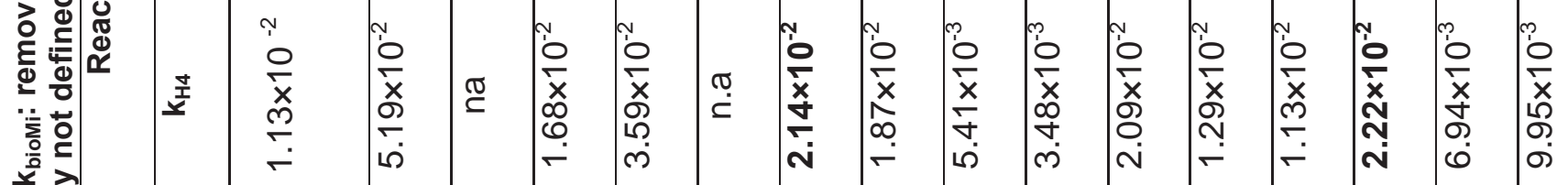

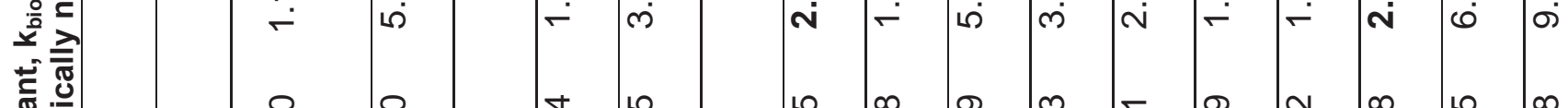

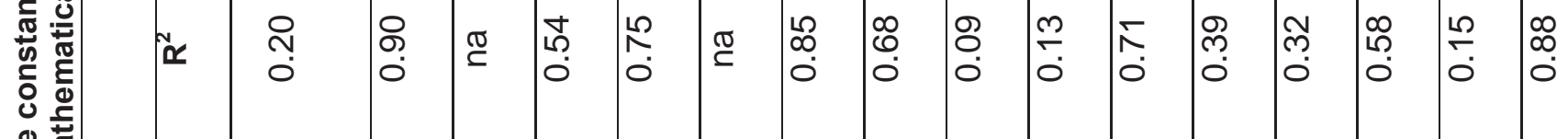

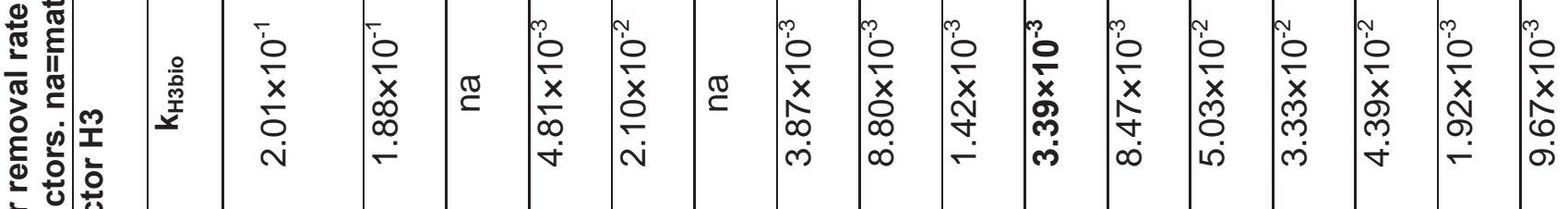

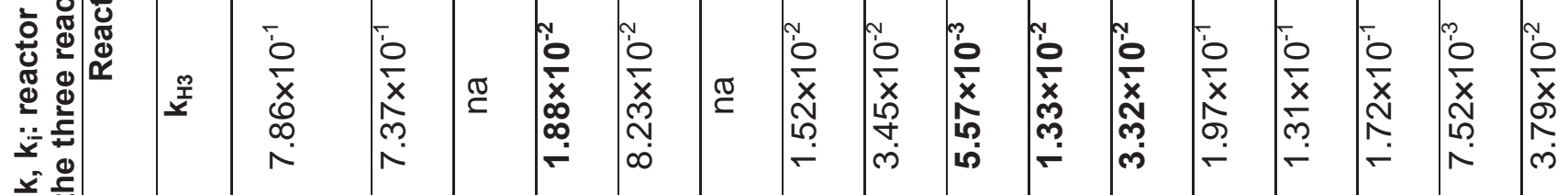

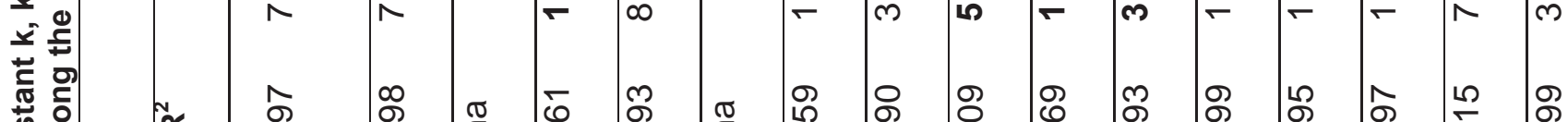

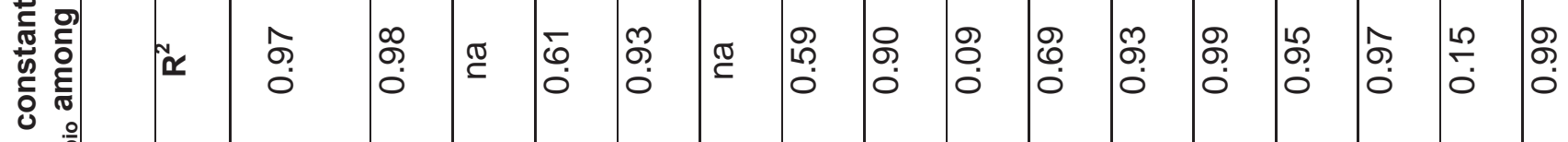

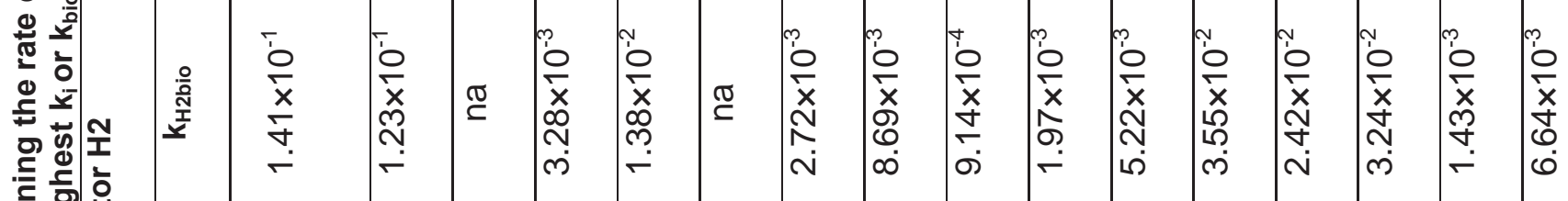

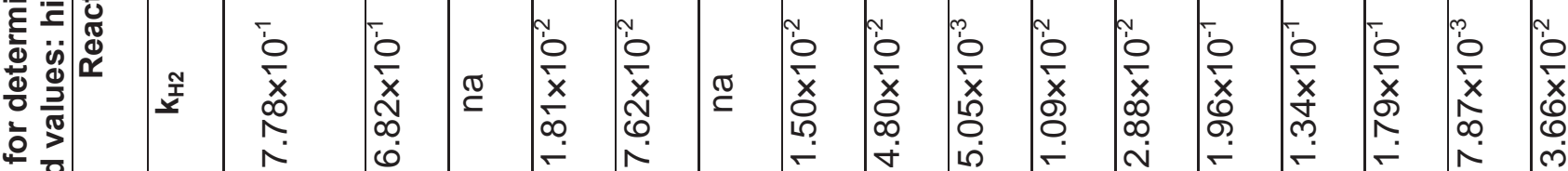

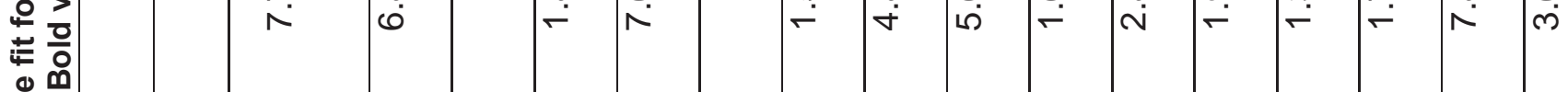

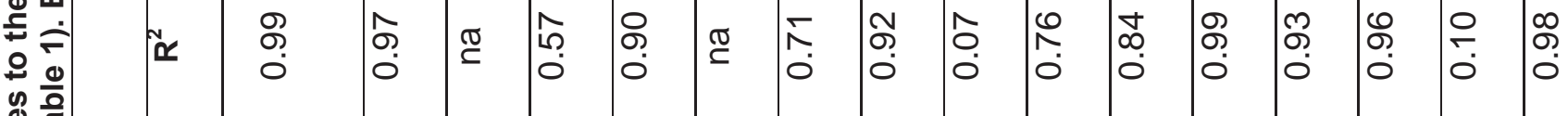

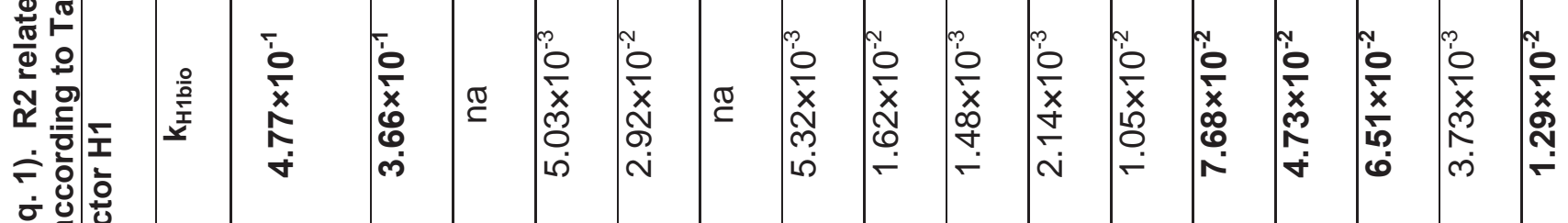

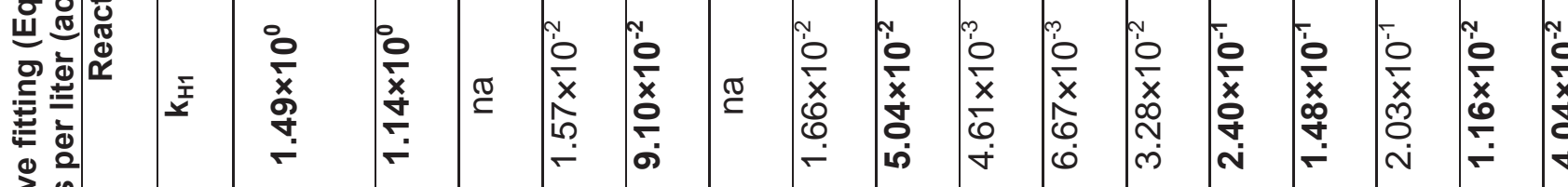

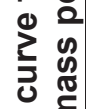

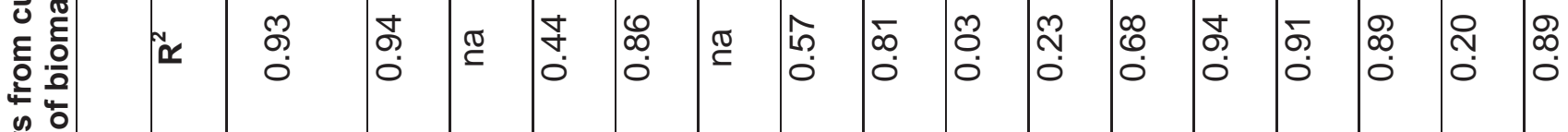

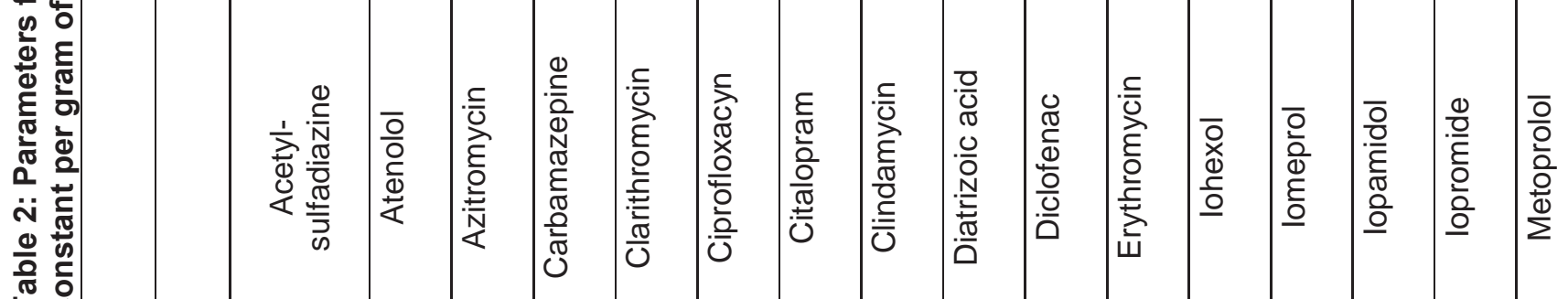




\begin{tabular}{|c|c|c|c|c|c|c|c|c|}
\hline 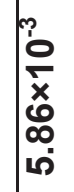 & 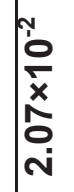 & 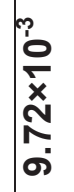 & 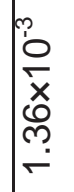 & $\begin{array}{l}0 \\
0 \\
0 \\
x \\
0 \\
0 \\
\infty \\
\infty \\
0\end{array}$ & $\begin{array}{l}\tilde{y} \\
\dot{y} \\
\dot{x} \\
0 \\
0 \\
\dot{m}\end{array}$ & 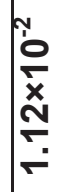 & 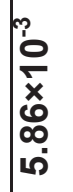 & 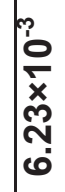 \\
\hline $\begin{array}{l}0 \\
-1 \\
\dot{x} \\
0 \\
-1 \\
0 \\
0\end{array}$ & 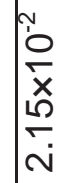 & $\begin{array}{l}0 \\
0 \\
\vec{x} \\
-1 \\
0 \\
-i\end{array}$ & 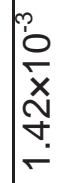 & $\begin{array}{l}m \\
0 \\
\vec{x} \\
\tilde{\omega} \\
\alpha \\
\infty \\
\infty\end{array}$ & 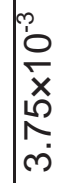 & 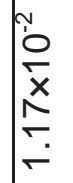 & $\begin{array}{l}0 \\
0 \\
0 \\
0 \\
0 \\
0 \\
0\end{array}$ & 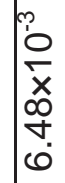 \\
\hline $\mid \begin{array}{l}0 \\
2 \\
0\end{array}$ & ְ. & 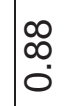 & Oי & 雚 & 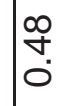 & 占 & 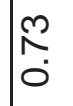 & ט. \\
\hline 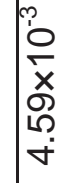 & $\begin{array}{l}m \\
0 \\
\tilde{x} \\
0 \\
0 \\
0 \\
\omega\end{array}$ & 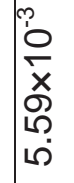 & 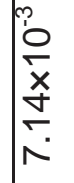 & $\begin{array}{l}1 \\
0 \\
\frac{x}{x} \\
0 \\
0\end{array}$ & 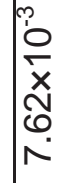 & $\begin{array}{l}0 \\
0 \\
0 \\
x \\
x \\
0 \\
r \\
r\end{array}$ & 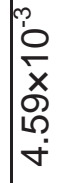 & $\begin{array}{l}m \\
0 \\
\hat{x} \\
0 \\
o \\
-i\end{array}$ \\
\hline 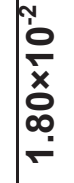 & 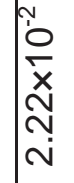 & 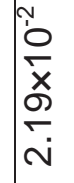 & $\begin{array}{l}0 \\
0 \\
\vec{x} \\
0 \\
0 \\
\sim \\
ن\end{array}$ & 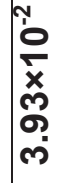 & id & 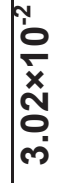 & 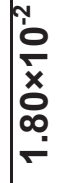 & 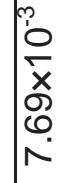 \\
\hline 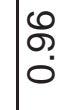 & 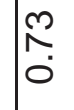 & $\begin{array}{l}\infty \\
\stackrel{\infty}{0} \\
0\end{array}$ & 政 & D. & 占 & $\mid \begin{array}{l}\infty \\
\infty \\
0 \\
0\end{array}$ & : & $\begin{array}{l}\infty \\
\infty \\
0\end{array}$ \\
\hline $\begin{array}{l}\dot{0} \\
\vec{x} \\
x \\
0 \\
0 \\
\dot{m}\end{array}$ & 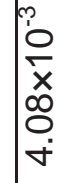 & 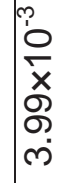 & $\begin{array}{l}0 \\
0 \\
0 \\
0 \\
0 \\
0 \\
0\end{array}$ & 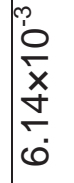 & 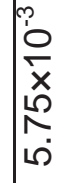 & 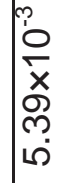 & $\begin{array}{l}m \\
0 \\
\dot{y} \\
0 \\
0 \\
0 \\
\dot{m}\end{array}$ & 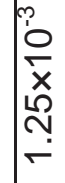 \\
\hline $\begin{array}{l}0 \\
\vec{x} \\
\hat{x} \\
\hat{R} \\
\dot{H}\end{array}$ & 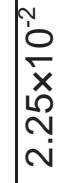 & $\begin{array}{l}\tilde{N} \\
\tilde{x} \\
\tilde{x} \\
\tilde{N} \\
\end{array}$ & 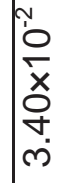 & 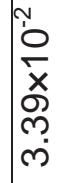 & 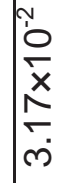 & 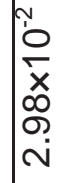 & 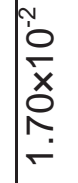 & $\begin{array}{l}0 \\
0 \\
0 \\
x \\
0 \\
0 \\
0 \\
0\end{array}$ \\
\hline O্ & $\begin{array}{l}0 \\
\stackrel{0}{0} \\
0\end{array}$ & 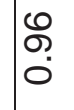 & $\mid \begin{array}{l}0 \\
0 \\
0\end{array}$ & $\begin{array}{l}\infty \\
\infty \\
\infty \\
0\end{array}$ & ס्. & סे & חֶ. & ס̊. \\
\hline 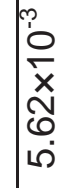 & 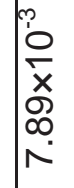 & 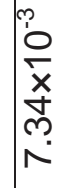 & 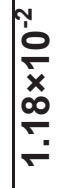 & $\begin{array}{l}m \\
0 \\
0 \\
x \\
x \\
0 \\
0 \\
\sigma\end{array}$ & 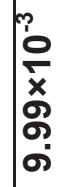 & $\begin{array}{l}0 \\
0 \\
0 \\
x \\
0 \\
0 \\
0 \\
r\end{array}$ & $\begin{array}{l}m \\
0 \\
\tilde{x} \\
\tilde{x} \\
0 \\
\dot{\omega} \\
\dot{n}\end{array}$ & 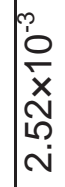 \\
\hline 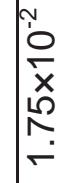 & 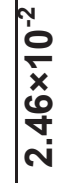 & 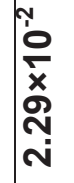 & 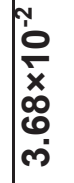 & 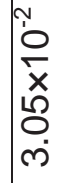 & 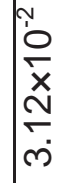 & 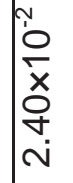 & 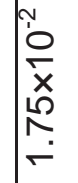 & '. \\
\hline 苍 & $\begin{array}{l}0 \\
\stackrel{0}{0}\end{array}$ & $\begin{array}{l}0 \\
2 \\
0\end{array}$ & 节 & $\stackrel{N}{N}$ & $\mid \begin{array}{l}-1 \\
0 \\
0 \\
0\end{array}$ & $\frac{0}{0}$ & $\begin{array}{l}\hat{\theta} \\
0 \\
0\end{array}$ & ্ְ. \\
\hline $\begin{array}{l}\frac{0}{0} \\
\frac{0}{N} \\
\frac{\pi}{\sigma} \\
\frac{0}{0} \\
\frac{0}{\alpha}\end{array}$ & $\begin{array}{l}\overline{0} \\
\frac{0}{0} \\
\frac{0}{0} \\
\overline{\frac{0}{0}} \\
\overline{0}\end{array}$ & \begin{tabular}{|l}
$\frac{\overline{0}}{\bar{\sigma}}$ \\
के \\
in
\end{tabular} & 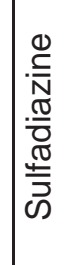 & 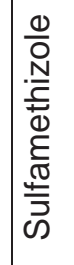 & 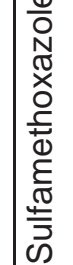 & 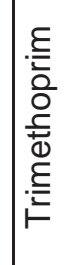 & 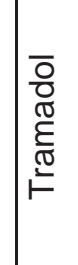 & 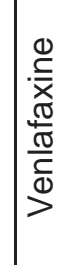 \\
\hline
\end{tabular}





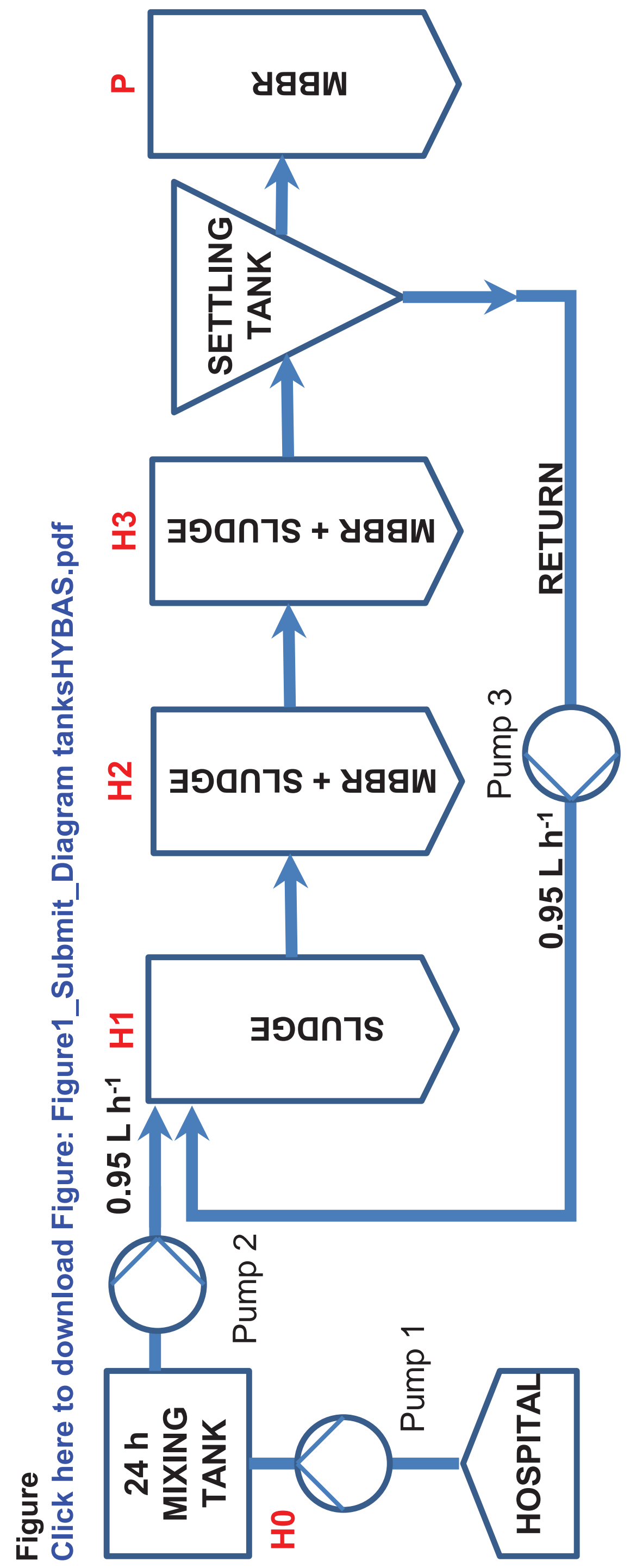


